\title{
Review on Conveyor Systems and Thermography
}

\author{
Ajith. B. Singh ${ }^{1, *}$, V. Rukkumani ${ }^{2}$, P. Manju ${ }^{1}$, R. Srinivasan² and Anie Selva Jothi.A ${ }^{3}$ \\ ${ }^{1}$ ICE, Sri Krishna College of Technology, Coimbatore \\ ${ }^{2}$ EIE, SriRamakrishna Engineering College, Coimbatore \\ ${ }^{3}$ ECE, Sri Krishna College of Engineering \& Technology, Coimbatore
}

Received 4 June 2019; Accepted 3 January 2020

\begin{abstract}
Dryer systems play a very significant role in most process industries. There are different composers of dryers based on its nature of drying and the item being utilized for drying. Some dryers use direct contact and some involve indirect contact for drying. But most widely used dryers are associated with a conveyor system which utilizes the transportation of materials along with smooth drying. Implementing a proper design of dryer along with a conveyor is very much essential and eliminates or reduces the non-uniformity in the drying of materials to improve the system efficiency. Some dryers work on electricity and some on solar systems. In this paper, we have prepared a literature review of the proposal and performance of various dryer and conveyor systems. Application of thermography for dryer systems will help in predicting the nonlinear nature exhibited in the dryer system thereby enhancing the protection and proper control for even drying of materials.
\end{abstract}

Keywords: Dryer systems, Conveyor systems, Thermography, Process control

\section{Introduction}

Drying is one among the imperative procedure associated with pressing, saving and expulsion of dampness in ventures. Outdoors or sun drying is the most widely recognized and least expensive technique utilized as a part out of every other place on earth particularly to dry farming items. Nourishment items are dried for safeguarding them for a more drawn out period. Leafy foods constitute a noteworthy piece of the nourishment items in creating nations. Drying is one of the regular and normal techniques which is utilized for protecting the leafy foods. Numerous assortments of natural products are occasional and a large portion of them are saved and expended in their dried shape to quite a while [10]. Drying evacuates the dampness inside the item by the warmth and its resulting dissipation from the item. Subsequently, drying includes concurrent warmth and mass exchange [25]. Exposed sun drying involves prolonged drying time and item quality is hard to control on account of lacking drying, high dampness, contagious development, and infringement of creepy crawlies, flying creatures and rodents, and others. Open sun drying likewise requires a huge space [17]. Warmth touchy items like nourishment, natural products, vegetables and pharmaceutical items on use of high temperature diminish item quality. For this situation, drying at low temperature and dampness is required to keep up the crisp shade of the item utilizing the desiccant framework [27-29]. The parameters used to assess the dryers incorporate physical highlights of the dryer, thermal execution, nature of the dried item, and price of dryer alongside repayment time. These factors are likewise appropriate for any dryer framework [30]. The assessment of ease drying strategies utilized as a part of creating nations depended on the accompanying contemplations: (I) starting

*E-mail address: ajith.b.singh@gmail.com

ISSN: 1791-2377 @ 2020 School of Science, IHU. All rights reserved. doi:10.25103/iestr.131.23 expense is low; (ii) framework is anything but difficult to introduce, work and keep up; and (iii) high drying rate and better item quality are delivered. In the determination of dryer composes, everything contributed at an alternate rate to the last score [31].

Numerous dryer writes have been utilized as a part of the household and industry areas. The dryers that are usually utilized are plate type, burrow type, drum type, fluidized bed type, splash type, streak type, revolving type, belt type, vacuum type and stop dryers. Among these dryers, the plate dryer is the most widely utilized due to its basic and monetary plan. Warming might be created by hot air stream over the plate, conduction from the warmed plate, or radiation from warmed surfaces. In a plate dryer, more items can be stacked as the plate are organized at various levels. Great wind stream appropriation will guarantee the last dampness substance of the dried out items on the plate are uniform. Regularly the dampness content is dictated by utilizing electronic adjust to get the distinction between a last and starting mass of the item [17].

The conveyor is utilized as a part of numerous ventures to carry products and items between phases of a procedure. Utilizing conveyor frameworks is the decent method to diminish the dangers of musculoskeletal damage in assignments or procedures that include manual taking care of, as they lessen the requirement for tedious lifting and conveying. These conveyors stay a ground-breaking material, taking care of hardware. They offer the chance to help efficiency, lessen item taking care of and harm, and limit work content in an assembling or circulation office. Conveyors are for the most part delegated either unit load conveyors which are intended to deal with particular identical units, for example, containers or else beds, and process conveyors which are intended to deal with free item, for example, sand, rock, espresso, treats, and so forth which are encouraged to hardware to promote tasks or blending. It is very regular for assembling manufactory to consolidate both 
process and unit load conveyors in its tasks. Roller conveyor isn't subjected to the multifaceted circumstance of stacking and still, it brings into being that it is composed with a sophisticated feature of security. On the off chance that we have updated basic parts like roller, shaft, bearings \& frame and so forth at that juncture, it is conceivable to limit the general mass of the assemblage. Driven belt conveyors are significantly long enough from 9 kilometers to 10 kilometers when contrasted with roller conveyor [1]. Belt-conveyors are further tolerable than other different methods for transporting mass materials. They work unnoticeably and recurrently on their own particular fenced in areas, which when attractive can be situated over the perplexity and wellbeing dangers of surface movement or in little passages outside of anyone's ability to see and hearing distance [32]. Belt conveyors are one among the principle transport gear in coalfield, driving barrel and strap is the crucial part. Rubbing standard is utilized to start machine-driven energy for strap conveyor. So rubbing is the main impetus and utilized to raise transportation effectiveness of conveyor along with the acceleration of the dynamic energy of barrel. Vitality sparing and proficiency, erosion, fire and security, upkeep and investigation are the other key variables of belt conveyor plan [33]. The greater part of the analysts concentrated on plan change to diminish the pulley (barrel) and strap catastrophes, upkeep fee, interruptions, vitality utilization \& in general cost of the framework for consistent transportation of material [2]. There are the floor and overhead conveyors accessible in the showcase. This kind of conveyor comprise of intensity and free, encased tracks, I-Beam, and towline based. These frameworks are utilized as a part of different ventures in view of the advantages they give [4]. Conveyor framework is normally utilized as a part of different segments including Automobile, Agriculture, Cement industry, Fertilizer, Food Processing, Chemical, Pharmaceutical, Coal mine, Limestone, Aerospace, Bottling and Canning and so on. The reason for such material taking care of gear is to exchange merchandise with high proficiency, less material transport time, no compelling reason to loosen off the chain or re-strain while changing Flights and simple establishment [5]. Appropriate consideration ought to be paid while planning the roller conveyor framework for the specific application. For instance, Gravity conveyors are outline without considering the torsional impact on the roller shell. As the application changes, the plan of the roller may differ as far as shaft, center, and shell get together. In the majority of the exploration papers, essential parts of roller conveyors like Roller, skeleton and segments and orientation were focused for weight streamlining. By applying essential outline ideas precisely as per the stacking conditions for every individual from the framework, one can plan the framework with a huge change of the segments [6]. Presently multi day's request of worth items from client, meticulousness, and fastidiousness in definite yield from the material management is essential because the manual material management has some restrictions and is required for best material dealing with framework emergence. It was discovered that such huge numbers of businesses are as of now utilizing manual dealing with which brings about the mistake in powder extents at end utilize, delay in activity because of manual blunders and different constraints [7]. All raising and passing on mechanisms can be separated by their working standards into dual extensive gatherings as sporadic movement and unceasing movement. Discontinuous movement incorporates a wide range of cranes, lift carriers, surface conveyor methods, airborne trams and links, skyscrapers and so forth.
Nonstop movement incorporates conveyors with pneumatic and water driven implies and so on which may be called as constant conveyor machines or passing on machines.

The conveyors are ordered into various classes those are as per the following chute, wheel, roller, chain, slat, level belt, Magnetic belt, troughed belt, bucket, vibrating, screw, pneumatic, cart on track, tow, trolley, power and free, monorail, sortation conveyors [8]. Conveyors are picked in view of the applications or procedures with a mix of at least two conveyor writes as per the need. The conveyor development speed is likewise chosen in light of the application it is being utilized. A few conveyors framework for transportation of containers, coal, sand, and so on require rapid and a few conveyors taking care of delicate and fine materials require to bring down the speed of developments.

Thermography is a system used for failure investigation approaches in electrical businesses. It is additionally the science devoted to the securing as well as handling of heat data from non-interaction estimation gadgets [36]. It depends on IR emission, a type of electromagnetic emission with lengthier wavelengths than the noticeable light. Any factual at a hotness above absolute zero emanates IR emission [37]. The mortal eye can't grasp this kind of emission. In this manner, IR estimating gadgets are essential to obtain and route this data [38]. An IR thermography camera is fundamentally an audio-visual recording gadget, which measures each edge or grouping put away, in a moved wavelength radiometric warm air and grasps, for the heat assessment. The hot emission indication identified by the IR camera is the consequence of the hotness subordinate dark body emission and the estimation of nearby infrared emissivity [34-35]. Infrared estimating gadgets get infrared radiation discharged by a protest and change it into an electric indication [39]. The utmost essential infrared gadget is the pyrometer, which creates a solitary yield utilizing a solitary sensor. Recently developed gadgets incorporate a variety of feelers to deliver a definite IR picture of the scene. The distinction between an obvious picture and an IR picture is, the observable picture is a portrayal of the replicated light of the scene, while the IR picture is the source which can be seen by an IR camera deprived of light. Pictures obtained utilizing IR cameras are changed over into observable pictures by allotting some shading to every IR vitality level. The outcome is an untrue-shading picture termed a thermogram [40].

\section{Modelling and Overview}

\subsection{Dryer Systems}

For every last item, there is a delegate bend that depicts the drying attributes for that item at a particular temperature, speed, and weight conditions. This bend is alluded to as the drying bend for a particular item. Figure beneath demonstrates an ordinary drying bend. Varieties in the bend will happen mainly in rate in respect to carrier velocity and temperature. Drying happens in three unique periods, or stages, which can be obviously characterized [48].

The principal stage, or introductory period, is the place sensible warmth is exchanged to the item and the contained dampness. This is the warming up of the item from the channel condition to the procedure condition, which empowers the resulting procedures to occur. The rate of dissipation increments significantly amid this period with for the most part free dampness being evacuated. In a few examples, pre-preparing can diminish or dispose of this stage. For instance, if the feed material is originating from a reactor 
or if the feed is preheated by a wellspring of waste vitality, the bay state of the material will as of now be at a raised temperature.

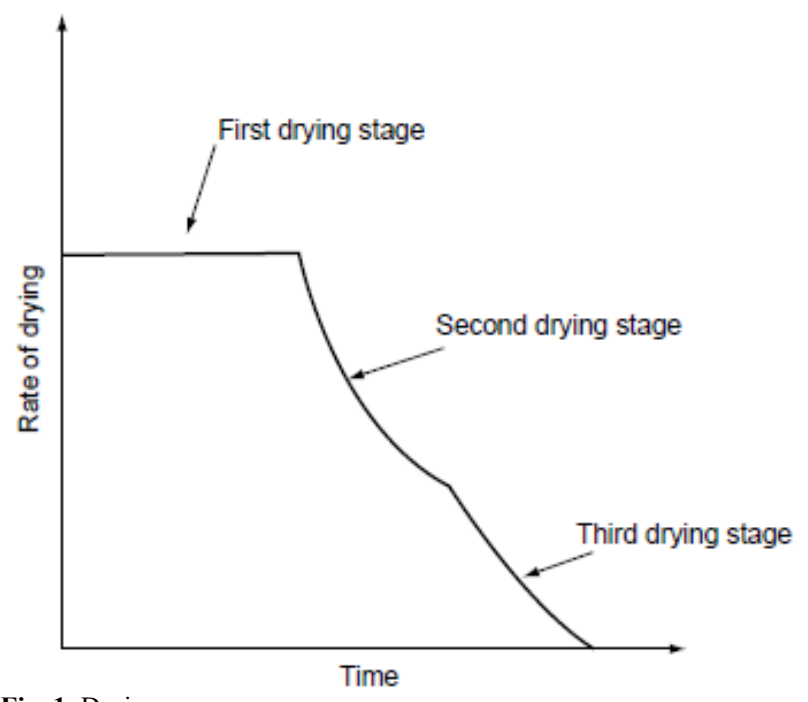

Fig. 1. Drying curve

The second stage, or steady rate period, is the point at which the free dampness holds on the surfaces and the rate of dissipation adjusts next to no as the dampness content diminishes. Amid this period, drying rates are high, and higher channel air temperatures than in resulting drying stages can be utilized without hindering impact to the item. There is a progressive and moderately little increment in the item temperature amid this period. Curiously, a typical event is that the time size of the consistent rate time frame may decide and influence the rate of drying in the following stage.

The third stage, or dwindling rate period, is the phase amongst which relocation of mugginess from the interior cracks of every single fragment to the peripheral surface turns into the coercing cog that decreases the desiccating rate.

A mistaken dryer for a specified tender is as yet a pitiable dryer, paying little respect to just how sound it is outlined. Take into account that negligible variations in the piece or physical assets of a specified item can impact its dehydrating attributes, dealing with characteristics, and so forth, prompting an alternate item and in approximately few circumstances leading to severe impasses in the dryer.

Assessments ought to be completed using "genuine" inputs and not a "recreated" one anywhere achievable. Albeit at this juncture we will concentrate just on the determination of dryer, as it is essential to take into account that practically speaking we should choose \& indicate a dehydrating framework which will incorporate pre dehydrating steps and additionally the post-drying phases of fumes gas cleaning, item accumulation, incomplete distribution of depletes, cooling of item, covering of item, agglomeration, and so on. The ideal financially savvy decision of dryer will depend, at times essentially, over these steps. Meant for instance, a solid pale raw material can be weakened to the propel-able semiliquid mixture, fine droplets and dehydrated in a splash dryer to deliver a triturate, or it might be made to pellets and dehydrated using a liquid bed or through exchange dryer or dehydrated using a revolving or liquid bed component. Additionally, now and again, it might be important to analyze the whole stream sheet to check whether the dehydrating issue can be rearranged or wiped out. Ordinarily, warm dehydrating is a request of-greatness more affordable than dissipation which, thusly, is many-overlay vitality effective than warm drying. Requests on item quality may not generally allow one to choose the minimum costly choice to construct exclusively with respect to warmth and mass exchange contemplations, nonetheless. Regularly, item quality necessities have a superseding impact on the determination procedure. As a base, the accompanying quantitative data is important to touch base at an appropriate dryer [49].

The complete modeling of the dryer process along with a belt conveyor with the technical specifications has been discussed by Kiranoudis (1994) [51]. According to the physical construction these dryers are classified into Rotary Dryers, Pneumatic/Flash Dryer, Spray Dryers, Drum Dryers, Fluidised Bed Dryers, Tunnel Dryers, Band Dryers, Hot Air Dryer, Infrared Dryers, Tray Dryers, Freeze Dryers, Vacuum Dryers and Microwave (MW) and Radio Frequency (RF) Dryer [41]

\subsection{Conveyor Systems}

The plan of belt conveyor structure embraces assurance of the veracious dimension of the strap conveyor segments and additional elementary constraint esteems in a direction to assure idyllic proficiency amidst mounding and evacuating situations. A ration of the sections which are used to model a conveyor system are roller diameter, dimension of the belt, capacity of the conveyor and speed of the conveyor, strap power and tautness, idler typography, pulley breadth, position and planning of pulley, motor, type of drive unit, regulating approach, projected presentation and maximum loading capacity.

Roller diameter must be thought about alongside the belt width. The equation for roller diameter is given by [53]

$D=\sqrt{(0.001273 * l * g)+d^{2}}$

The complete diameter is denoted as ' $\mathrm{D}$ ' in meters, the central diameter is denoted as ' $\mathrm{d}$ ' in meters, the strap length is denoted as ' 1 ' in meters and the strap chunkiness is denoted as ' $\mathrm{g}$ ' in millimeters. The dimension of the strap which is to be rolled is given by [53]

$L=\left[d+\left\{\left(\frac{D-d}{2}\right) * \pi * N\right\}\right]$

The above equation can be rewritten as given below,

$\mathrm{L}=\mathrm{H} * \pi * \mathrm{~N}$

The external diameter of the roll is denoted as ' $\mathrm{D}$ ' in meters, the diameter of the roll core is denoted as ' $\mathrm{d}$ ' in meter, the no. of wraps of the strap is denoted as ' $\mathrm{N}$ ' and the elevation of the middle core is symbolized as ' $\mathrm{H}$ ' in meters. The total conveyor belt length is given by

$l=\frac{a}{\theta}$

here 1 is the total conveyor length in meters, $a$ is the horizontal distance in meters and $\theta$ is the inclination angle in degrees. The basic length of the belt is given by two times the length of the conveying path. It is given as an equation below,

$\mathrm{B}=2 * \mathrm{f}$

where $\mathrm{f}$ is the total conveying path in meters and $\mathrm{B}$ is the basic length of the belt in meters. The connection between the most 
extreme strap speed, roller breadth, and the comparative upheaval or revolution every moment is specified as

$$
n=\frac{V * 1000 * 60}{D * \pi}
$$

The number of revolutions per minute is mentioned as ' $n$ ', roller diameter is mentioned as ' $\mathrm{D}$ ' in $\mathrm{mm}$ and belt speed is mentioned as ' $\mathrm{V}$ ' in $\mathrm{m} / \mathrm{s}[53,54]$. The breadth of the driver \& driven pulley is uttered by the type and dimension of conveyor belting. The breadth of the pulley should be outlined to such an amount that it doesn't put unjustifiable strain or stress on the strap. The total span of a strap conveyor in meters is the extent from the crucial point of pulley parallel to strap stripe. Strap span is subject on both the pulley breadths and focus partings [55].

$\mathrm{S}=\mathrm{d} * \pi$

The capacity of the conveyor is the multiplication of swiftness and strap cross-sectional zone and is denoted in $\mathrm{kg} / \mathrm{sec}$. The equation is given by

$\mathrm{C}=3.6 * \mathrm{~V} * \mathrm{~A} * \rho$

here $\mathrm{C}$ is the conveyor capacity in $\mathrm{kg} / \mathrm{sec}$, the velocity of the conveyor belt is mentioned as ' $\mathrm{V}$ ' in $\mathrm{m} / \mathrm{s}$, A is the crosssectional area of the belt in $\mathrm{m}^{2}$, and $\rho$ is the material density in $\mathrm{kg} / \mathrm{m}^{3}$. The conveyor strap distance across must be amply widespread to achieve the material bump assessment [53]. The viewpoint of the supplement is a standout amongst the utmost vital qualities in deciding the conveying ability as it straightforwardly administers the cross-sectional region of the factual in the strap and thus the bulk being passed on. The viewpoint of supplement depends on the roughness among the conveyor strap, the factual and how the factual is loaded to the strap. The steeper the conveyor, grander the strap capability and the slighter the viewpoint of the supplement [56]. The belt capacity given in tonnes/hr of a conveyor which has three equal roll idler is given by [53]

$$
C=\frac{\rho * V * C_{T} * C_{f}}{1000}
$$

Capacity is mentioned as ' $\mathrm{C}$ ' in tonnes/hr of a strap conveyor with three identical roll idler, $\mathrm{C}_{\mathrm{T}}$ is the capability of troughed straps with three roll identical dimension idler, $\rho$ is the concentration of the material in $\mathrm{kg} / \mathrm{m}^{3}, \mathrm{C}_{\mathrm{f}}$ is the capacity factor and is a constant, and velocity of the strap is mentioned as ' $\mathrm{V}$ ' in $\mathrm{m} / \mathrm{s}$. If the straps are running horizontally and are uploaded with input equally, then the volumetric belt load also is given by

$L_{v}=\frac{L_{c}}{W}$

here $\mathrm{L}_{\mathrm{V}}$ is the volumetric load on the belt in $\mathrm{m} 3 / \mathrm{hr}, \mathrm{L}_{\mathrm{C}}$ is the load capability of the strap conveyor in tonnes/hr and specific weight of the conveyed material is mentioned as' $\mathrm{W}$ ' in tonnes $/ \mathrm{m} 3$. The quantity of material $\mathrm{M}$ or cargo per meter loaded over the strap conveyor denoted in $\mathrm{kg} / \mathrm{m}$ is given by

$M=\frac{C}{V * 3.6}$

conveyor capacity is mentioned as ' $\mathrm{C}$ ' in tonnes/hr and the velocity of the conveyor strap ' $\mathrm{V}$ ' in $\mathrm{m} / \mathrm{s}$. The assurance of strap width is to a great extent an element of the amount of conveyed factual which is demonstrated by the outline of the conveyor strap. The conveyor strap distance across must be adequately wide to accomplish the factual irregularity estimate [57]. When the extent of the strap is longer, the control essential for the conveyor to operate is more and the greater the upright separation of the lift, the complex the intensity of control required. The control required to operate the pulleys is given by

$C P=\frac{F_{E f f * V}}{1000}$

here $F_{E f f}$ is the overall lateral force at the fringe of the drive pulley in terms of Newton and CP is the control required to operate the belt in KW. For calculating the tangential force, the above equation can be rewritten as

$F=\frac{C P * 1000}{V}$

The control needed by the conveyor to produce the lifting force is given by,

$F=\frac{3.75 * H * C}{1000}$

where $\mathrm{CP}$ is the control of the conveyor in kilowatts, lifting height is mentioned as ' $\mathrm{H}$ ' in meters and $\mathrm{C}$ is the conveyor capability in tonnes per hour. The strap of the conveyor dependably encounters elastic load because of the revolution of the electrically powered drive, mass of transported resources and because of idlers. The strap strain must be sufficiently awesome to predict the slippery between the drive pulley and strap [58]. Strap strain at a consistent or stable stage is given by

$\mathrm{T}_{\mathrm{ss}}=1.37 * \mathrm{f} * 1 * \mathrm{~g}\left[\left(2 \mathrm{M}_{\mathrm{i}}\right)+\right.$

$\left.\left(2 \mathrm{M}_{\mathrm{b}}+\mathrm{M}_{\mathrm{m}}\right) \operatorname{Cos} \theta\right]+\left(\mathrm{H}^{*} \mathrm{~g} * \mathrm{M}_{\mathrm{m}}\right)$

here $T_{\mathrm{ss}}$ is the belt tension or strain at consistent or steady state measured in Newtons, $\mathrm{f}$ is the coefficient of friction or resistance, 1 is the conveyor length in meters, $g$ is the acceleration due to gravity in $\mathrm{m} / \mathrm{s}^{2}, \mathrm{M}_{\mathrm{i}}$ is the load or mass due to the idlers in kilograms, $M_{b}$ is the load or mass due to the belt of the conveyor in kilograms, $\mathrm{M}_{\mathrm{m}}$ is the load or mass due to the materials being transported in kilograms, $\theta$ is the inclination angle of the conveyor system in degrees and $\mathrm{H}$ is the vertical height of the conveyor system in meters. All through the beginning of the conveyor structure operation, the strain on the strap will be more than the stable stage strain. The strap tautness, while the conveyor starts to run, is,

$\mathrm{T}_{\mathrm{ss}}=\mathrm{T}_{\mathrm{st}} * \mathrm{~K}_{\mathrm{s}}$

here $K_{s}$ is called the start-up factor which is a constant and $T_{s t}$ is the belt tension during the start of the operation. Considering an inclined belt with pulley arrangements, the tension at head pulley and the tail pulley is given by

$\mathrm{T}_{\text {High }}=\mathrm{T}_{\mathrm{e}}+\mathrm{T}_{1}$

$\mathrm{T}_{\text {High }}=\mathrm{T}_{\mathrm{e}}+\mathrm{T}_{1}+\left(\mathrm{T}_{\mathrm{b}}-\mathrm{F}_{\mathrm{r}}\right)$

here $T_{1}$ is the strain or tension at any particular point, $T_{b}$ is the tension occurring on the belt, $F_{r}$ is the friction occurring on the return side and $\mathrm{T}_{\mathrm{e}}$ is the effective tension measured in Kilo Newtons and is given as 
$\mathrm{T}_{\mathrm{e}}=\mathrm{F}_{\mathrm{Te}}+\mathrm{F}_{\mathrm{L}}+\mathrm{T}_{\mathrm{sl}}$

where $\mathrm{F}_{\mathrm{Te}}$ is the total empty friction or resistance on the belt, $\mathrm{F}_{\mathrm{L}}$ is the friction occurring due to the load of materials and $\mathrm{T}_{\mathrm{sl}}$ is the tension occurring on the slope due to the load. The total empty friction is given by

$\mathrm{F}_{\mathrm{Te}}=\mathrm{F}_{\mathrm{e}}+\left(\mathrm{L}+\mathrm{F}_{\mathrm{t}}\right) * \mathrm{~W} * 9.81 \mathrm{e}^{-3}$

where $\mathrm{F}_{\mathrm{e}}$ is the equipment friction factor which is a constant, $\mathrm{W}$ is the mass or weight of the material or load along with the belt in $\mathrm{kg} / \mathrm{m}, \mathrm{L}$ is the length of the conveyor system in meters and $F_{t}$ is the terminal friction constant. The friction occurring due to the load of the materials is given by

$\mathrm{F}_{\mathrm{L}}=\mathrm{F}_{\mathrm{e}}+\left(\mathrm{L}+\mathrm{F}_{\mathrm{t}}\right) * \frac{C}{V * 3.6} * 9.81 \mathrm{e}^{-3}$

The capacity of the conveyor strap is measured in tonnes/hour and mentioned as' $\mathrm{C}$ '. The friction occurring on the return side is given by

$\mathrm{F}_{\mathrm{r}}=\mathrm{F}_{\mathrm{e}} * \mathrm{~W} * \mathrm{~L} * 0.4 * 9.81 \mathrm{e}^{-3}$

The tension occurring on the slope due to the load is given by the equation,

$T_{s t}=\frac{C * H}{3.6 * V} * 9.81 e^{-3}$

The highest tension occurring in the conveyor system will be the strap strain at the points where the conveyor system involves a greater strain. It is given by the equation

$\mathrm{T}_{\mathrm{m}}=(1+\mathrm{K}) * \mathrm{~T}_{1}$

where $\mathrm{K}$ is called the drive factor of conveyor arrangement. The maximum unitary strain of the conveyor system belt is given by

$T_{m u}=\frac{T_{m} * 10}{b}$

where $b$ is the width of the conveyor belt in meters. The total power occurring on the conveyor strap is given by

$\mathrm{P}_{\mathrm{b}}=\mathrm{T}_{\mathrm{e}} * \mathrm{~V}$

Strap strain of a conveyor framework is of a changing an incentive besides the framework flight and is represented by the accompanying impacting aspects like the span and path of the framework, total and plan of pulley, qualities of the moving and decelerating gear, sort and area of the strap begin gadgets and working \& stacking condition of the framework [59]. Shaft configuration comprises basically of assurance of the right shaft diameter across that will guarantee agreeable unbending nature and quality when the pole or shaft is transmitting movement under various working and stacking conditions. The estimations of belt width and pulley diameter across helps in choosing the measure of shaft breadth from various conveyors handbook. Minimal Programmable Controllers also called application controllers can be utilized for the control of the framework. These controllers can be utilized for time control and supervisory capacities, like conveyor speed control, speed control of individual drives, speed and belt slip control, stack equilibration between two driving drums and speed contrast control between two engines on one driving drum, etc [60]. Idlers are introduced at graduated dividing to guarantee that the droop because of load changes contrarily with the strain in the belt. The total load which is live on the conveyor belt is given by

$\mathrm{T}_{\mathrm{L}}=\mathrm{L}_{\mathrm{L}} * \mathrm{~L}_{\mathrm{C}}$

here $\mathrm{L}_{\mathrm{L}}$ is the total load on the conveyor in kilograms and $\mathrm{L}_{\mathrm{C}}$ is the length of the conveyor belt in meters. There will be a presence of a dead load on the conveyor system which is the summation of roller weight, belt weight, and drive pulley weight. The idlers can be placed at distinguished spacing and this spacing can be equated as,

$I_{S}=\frac{8 * T * S}{M \rho * 9.81 * e^{-3}}$

here $\mathrm{T}$ is the tension at a particular point which can be measured in kilo Newtons, $\mathrm{M} \rho$ is the mass or weight of the conveyor belt and live load and at last $\mathrm{S}$ is the spacing of the idlers given in percentage. Generally, the recommended idler spacing is one meter for the belt conveyors for huge load transporting belt conveyors [57]. When considering the pulley diameter some of the main factors which we have to take into account is the wrap angle, belt speed, system of belt strain, belt tension, the width of the belt, splice type which is being used for the conveyor belt. The diameter of the pulley and coupling sizes are obtained from the catalogs available for different conveyor systems and the length of pulley wrap in the terminals is given by,

$\mathrm{L}_{\mathrm{PW}}=2 * \pi * \mathrm{D}$

here $\mathrm{D}$ is the diameter of the pulley measured in meters. The driving pulley system can be wrapped which will increase the resistance in the conveyor belt and improve the transmission or spread between the pulley and the belt of the conveyor system [61]. Wrapping up of the pulley with elastic materials will keep the pulley clean and increase the duration of resistance. Using a corrugated wrapping removes the moisture and enhances the resistance or friction. The effective pulling force in the belt is given by

$\mathrm{F}_{\mathrm{Eff}}=\mu_{R} * g\left(M_{t}+\frac{M_{B}}{2}\right)+\mu_{P} * g\left(\frac{M_{B}}{2}+M_{i}\right)$

here $F_{E f f}$ is the effective pulling force measured in Newtons, $\mu_{R}$ is the coefficient of friction with roller support, $\mu_{p}$ is the coefficient of friction with skid plates, $g$ is the acceleration due to gravity, $\mathrm{M}_{\mathrm{t}}$ is the total load of the transported materials in kilograms, $M_{B}$ is the total mass of the belt in kilograms and $M_{i}$ is the total mass of the idlers in kilograms. The above equation's result can be used to find the power calculations of the belt conveyor. Similarly, the acceleration of the conveyor belt can be found by the equation given below,

$A_{c}=\frac{T_{s t}-T_{S S}}{\left[L *\left(2 M_{i}+2 M_{B}+M_{t}\right)\right]}$

The other parameter which is to be considered along with the acceleration of the belt is the breaking strength of the conveyor belt which chooses the required belt for the application. The breaking strength of the belt is given by, 
$B_{b r s}=\frac{C_{f f^{*}} P_{d p}}{C_{l f} * V}$

here $\mathrm{C}_{\mathrm{ff}}$ is the friction factor of the conveyor belt, $\mathrm{P}_{\mathrm{dp}}$ is the power exerted at the driving pulley arrangement measured in kilowatts, $\mathrm{V}$ is the velocity of the conveyor belt and $\mathrm{C}_{\text {lf }}$ is the breaking strength loss factor of the conveyor belt. Considering the selection of motors, based on the application the motor may be an AC motor, DC motor, Gear motor, Helical motor, etc with transmission or gear wheel systems. The threshold power requirement for the range of motor is given by,

$P_{T h}=\frac{P_{d p}}{\eta}$

here $\mathrm{P}_{\mathrm{Th}}$ is the threshold power required for motor measured in kilowatts, $\eta$ is the efficiency of the gear systems used and $P_{d p}$ is the power exerted at the drive pulley arrangement. The horsepower of the motor used is calculated by using the equation,

$H P_{m}=\frac{H P_{R}}{\eta}$

here $\mathrm{HP}_{\mathrm{R}}$ is the minimum horsepower required which is given by the equation,

$H P_{R}=H P_{E}+H P_{t}+H P_{e m}$

here $\mathrm{HP}_{\mathrm{E}}$ is the horsepower required to move the conveyor belt at bare conditions, $\mathrm{HP}_{\mathrm{t}}$ is the horsepower required to transport the material level plane and $\mathrm{HP}_{\mathrm{em}}$ is the horsepower required to take material up vertically. The twisting moment of the motor is given by

$M_{t}=0.5 * D *(f+(\mu * m * g))$

here $\mathrm{D}$ is the diameter of the pulley measured in meters, $\mathrm{f}$ is the force required for motion in Newtons, $\mu$ is the coefficient of friction, $m$ is the mass of the material being transported by the conveyor belt and the belt in kilograms per meter and $g$ is the acceleration due to gravity. The total number of rotations made by the motor is given by the equation,

$N=\frac{9550 * 1000 * P}{M_{t}}$

The cycle time of the conveyor system to complete one full cycle is given by the equation,

$C_{f}=\frac{2 * L}{V}$

here $\mathrm{L}$ is the length of the conveyor belt measured in meters and $\mathrm{V}$ is the velocity of the belt. The torque being developed by the motor rotation is given by,

$T_{c}=\frac{9.55 * P}{N}$

here $\mathrm{P}$ is the power required for the conveyor to move or operate, $T_{c}$ is the torque developed by the conveyor movement measured in kilo Newton-meter.

\subsection{Thermography}

The tale of IR imaging has begun amid World War II [65]. Hence, this procedure has stretched out to different fields, like medication, support \& maintenance, horticulture, mechanical, process industries, electrical, automobiles, gas detection, aerial survey, etc [66]. The essential wellspring of infrared radiation is heat or heat radiation. It is the radiation created by the movement of molecules and atoms in a material. The higher the temperature, the more the molecules and atoms move and the more IR radiation they deliver. Any material which has a temperature above absolute zero (- 459.67 degrees Fahrenheit or - 273.15 degrees Celsius or 0 degrees Kelvin), emanates the IR radiation. Absolute zero is the temperature at which all nuclear and sub-atomic movement stops. Indeed, even products that we consider as being extremely cold, also produce infrared. At the point when a material isn't sufficiently hot to emanate visible light, it will transmit the vast majority of its vitality in the infrared. For instance, hot charcoal may not emit light but rather it emits infrared radiation which feels like heat. The hotter the material, the more infrared radiation it transmits. In 1860, Gustav Robert Kirchhoff characterized a blackbody as a surface that neither reflects nor transmits occurrence radiation. Rather, a blackbody ingests all occurrence radiation independent of course and wavelength. Notwithstanding be an impeccable absorber, a blackbody is likewise a flawless radiator. Along these lines, all radiation leaving a blackbody is transmitted by the surface and no surface can emanate more vitality than a blackbody. The produced radiation is an element of the wavelength and temperature however free of the course $[67,68]$. Similarly, a grey body is a body with constant emissivity over all kinds of temperature ranges. In this manner, a genuine dark body is characterized by an emissivity of 1 . The distinction in the conduct of a normal form concerning the black body is demonstrated by parameter spectral emissivity [69]. According to Plank's Law, the spectral distribution of radiation concentration from the black body will be given by,

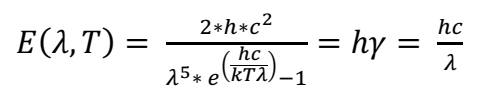

where $\mathrm{h}$ is the Planck's constant $\left(6.62 * 10^{-34} \mathrm{Js}\right), \mathrm{c}$ is the velocity of light, $\lambda$ is the wavelength measured in meters and $\mathrm{T}$ is the temperature measured in Kelvin. Using Planck's equation the spectral distribution can be found corresponding to the maximum possible emission from a normal body. After this discovery Wilhelm Carl Werner Otto Fritz Franz Wien discovered that the product of the wavelength at which maximum radiation is emitted by a body and the body's temperature will be equal to a constant which is given by,

$T * \lambda_{m}=2897$

where $\mathrm{T}$ is the temperature measured in Kelvin and $\lambda_{\mathrm{m}}$ is the maximum radiation wavelength emitted by a body measured in micrometers. The above equation can be rewritten as,

$\lambda_{m}=\frac{2897}{T}$

For any real body the sum of energy being absorbed, reflected and transmitted will be the total energy of a body or equal to 1. According to Kirchhoff's law of thermal radiation, a perfect black body will have,

$$
\alpha=\epsilon
$$


here $\alpha$ is the absorptivity and $\epsilon$ is the emissivity. But for a real body, the equation slightly varies and is given by,

$\alpha+\epsilon+\tau=1$

where $\tau$ is the transmissivity of the real body. The total energy of the body can be therefore given by

$\mathrm{E}_{\mathrm{Tot}}=\mathrm{E}_{\mathrm{abs}}+\mathrm{E}_{\text {trans }}+\mathrm{E}_{\text {Ref }}$

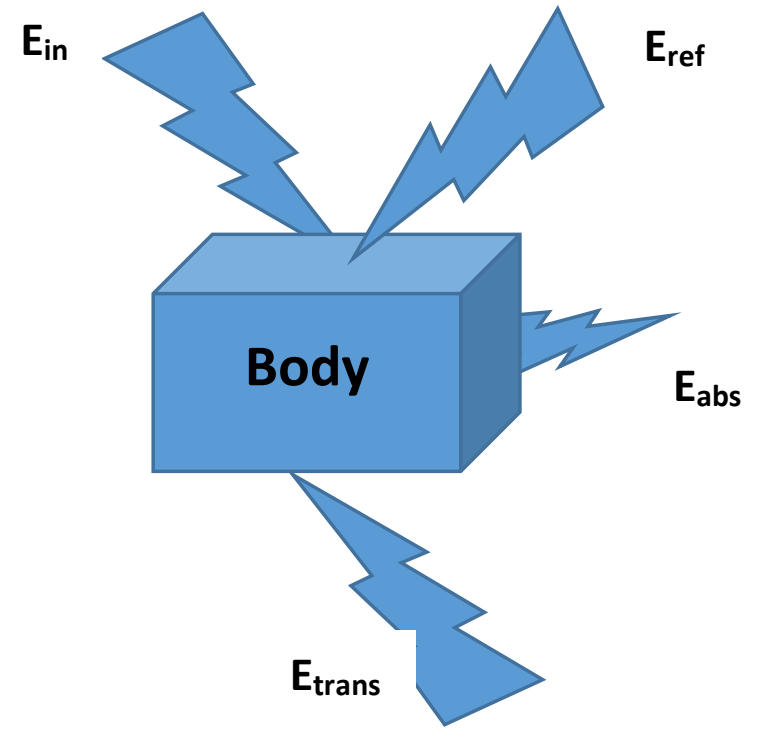

Fig. 2 .Total energy through a body

Before Kirchhoff's law of thermal radiation there came into existence the law proposed by Josef Stefan and Ludwig Boltzmann known as Stefan-Boltzmann law which is given by,

$E=\sigma * T^{4}$

where $\sigma$ is the proportionality constant which is given as $5.670373 * 10^{-8}$. The power radiated by the body can be calculated by

$E=A * \varepsilon * \sigma * T^{4}$

where $A$ is the area of the object in square meters, $\varepsilon$ is the emissivity of the object and $\mathrm{T}$ is the temperature measured in Kelvin. The Stefan-Boltzmann law is therefore called the law of black body emission [67, 70, 71]. Later Fumihiro Sakuma, Akira Ono and Susumu Hattori proposed Sakuma - Hattori equation which states that the electromagnetic radiation produced from a hot body will be based on its temperature. This equation is almost a derivation from Planck's equation which is given by,

$S(T)=\frac{C}{e^{\left(\frac{C_{2}}{T \lambda_{x}}\right)}-1}$

where $\mathrm{C}$ is a constant, $\lambda_{\mathrm{x}}$ is the temperature dependent wavelength and $c_{2}$ is the second radiation constant and $\mathrm{T}$ is the temperature measured in Kelvin.

The electromagnetic spectrum comprises of diverse particle emissions like cosmic rays, gamma rays, x-rays, ultraviolet, a tinny section of visible light, infrared, terahertz waves, microwaves, radar waves, radio waves and broadcast group waves [73].

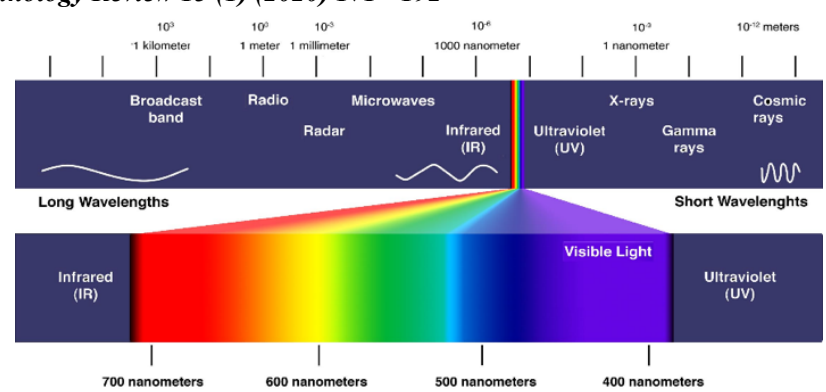

Fig. 3 . Electromagnetic spectrum [79].

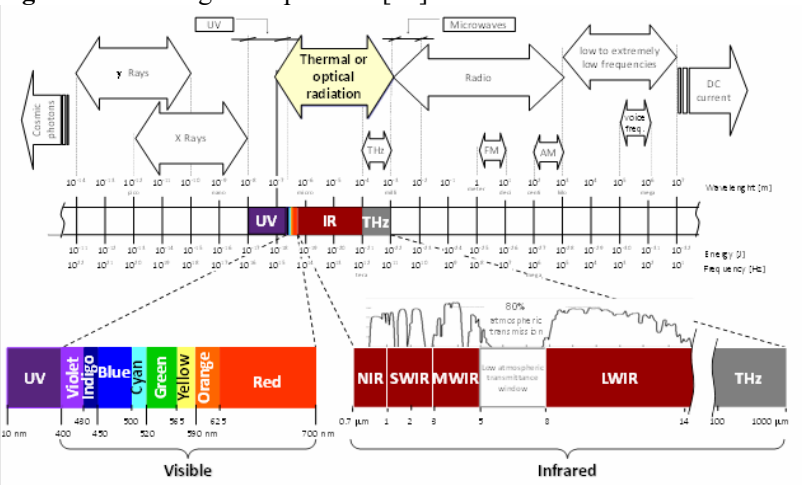

Fig. 4 . Visible \& Infrared spectrum [80].

From the figure there are four infrared spectral bands which are the near infrared band (NIR) which approximately from $0.75 \mu \mathrm{m}$ to $1 \mu \mathrm{m}$, short-wave infrared band (SWIR) which approximately ranges from $1 \mu \mathrm{m}$ to $2.5 \mu \mathrm{m}$, mid-wave infrared (MWIR) which approximately ranges from $3 \mu \mathrm{m}$ to $5 \mu \mathrm{m}$ and long wave infrared (LWIR) which approximately ranges from $7 \mu \mathrm{m}$ to $14 \mu \mathrm{m}[73,74,75]$. As the infrared radiations are invisible radiations, the infrared cameras are required to attain and detect these invisible info and mark it as visible data [76]. Among these bands the normal temperature region measures form $8 \mu \mathrm{m}$ to $14 \mu \mathrm{m}$ and for higher temperatures it ranges from $2 \mu \mathrm{m}$ to $3 \mu \mathrm{m}$. The normal temperature region comes in the band of LWIR which has the band of peak emissions and atmospheric transmittance [77, 78].

When a thermographic analysis is to be made the factors to be taken into account are spatial resolution, changes in emissivity, reflections, solar heating, induction, and wind flow rate [69]. The infrared camera and its lens have a spatial resolution that defines the size of the smallest object whose temperature can be measured from various distances. The resolution is expressed in milliradians and helps to determine the size corresponding to a pixel at various distances. The geometric resolution of the object depends upon field of view (FOV) of lens, instantaneous field of view (IFOV) of lens, distance from the object and the no. of pixels of the sensor or sensor size [69]. The lens and processor system used in thermography uses a correction which is formed by using inverse square law which is given by,

$\frac{I_{1}}{I_{2}}=\frac{D_{1}^{2}}{D_{2}^{2}}$

$I_{2}=\frac{D_{2}^{2} * I_{1}}{D_{1}^{2}}$

where $I_{1}$ and $I_{2}$ are the intensities at distances $D_{1}$ and $D_{2}$. As the atmosphere changes with distances this formula seems correct with mathematics but proves wrong with physics. Flir made cameras uses this correction. Another factor to be 
considered in thermography camera is the optical and digital zoom. Optical zoom use more focal length lenses but in digital zoom only image is enlarged electronically. As focal length increases the image size also increases. Therefore, when making measurements or producing a thermogram, three sets of characteristics must be considered which are characteristics of the target surface, characteristics of the transmitting medium and characteristics of the measuring instrument. Thermography camera has a starring array using which the IFOV is calculated. The IFOV is calculated using the formula,

IFOV $=\frac{\text { Target size in } \mathrm{mm}}{\text { Distance in } \mathrm{m}}$

The IFOV is further classified into two types as horizontal and vertical field of view measured in terms of degrees of angle. The HFOV and VFOV are calculated based on the detector or sensor element size or pixels. Smaller the angle better the sensitivity of the camera. The minimum detectable target size is given by,

\section{$M D T=I F O V *$ Distance in $m$}

If ' $a$ ' is the actual detector size, ' $A$ ' is the total pixel size, ' $\mathrm{FL}$ ' is the focal length and ' $\mathrm{B}$ ' is the pitch of focal plane array then the fill factor is given by

$$
\text { Fill Factor }=\frac{a}{A}
$$

This fill factor shall be greater than 0.75 . The detector angular sub trends and detector cut-off frequency is given by

$$
\begin{aligned}
& D A S=\frac{a}{F L} \\
& D C F=\frac{1}{D A S}
\end{aligned}
$$

The pixel angular subtrends and the system cutoff frequency is given by,

$$
\begin{aligned}
& P A S=\frac{B}{F L} \\
& S C F=\frac{1}{P A S}
\end{aligned}
$$
by,

The sampling frequency to the IR camera sensor is given

$$
S F=2.56 * S C F
$$

While considering the dynamic range of the camera we must consider the thermal resolution, thermal sensitivity, minimum resolvable temperature, minimum detectable temperature and noise equivalence difference temperature. MDT is a measure to detect the object and depends upon the resolution and sensitivity of the imaging camera. MRT is used to predict the range at which a target can be detected, recognized, or identified. It has become the standard metric of image quality. Smaller the MRT better the infrared camera and is given by,

$M R T=\frac{K_{S N R} * N E D T * K_{F a c t o r}}{M T F}$

where $K_{\mathrm{SNR}}$ is the empirical constant that matches the theoretical prediction to measured values, $\mathrm{K}_{\text {Factor }}$ represents various eye "filters" that interpret the various noise components and MTF is the system's modulation transfer function. When considering the sources of errors, the basic sources are lens aberration, amplifier frequency response, defocus, and additional error causes. The noise equivalence difference temperature is given by,

$N E D T=\frac{V_{R M S}}{S i T F}$

where SiTF is the signal transfer function which is given as $\frac{\Delta V}{\Delta T}$. The dynamic range of the camera is given by,

$D R=\frac{2^{n_{* N E D T}}}{\Delta T}$

When the dynamic range is more the sensitivity of the camera is less and vice versa. These are the main details to be considered when selecting a thermography camera.

\section{Conveyor \& Its Types}

The conveyor systems are categorized into diverse groupings and are given as chute, wheel, roller, chain, slat, flat belt, Magnetic belt, troughed belt, bucket, vibrating, screw, pneumatic, cart on track, tow, trolley, power and free, monorail, Sortation conveyors [8]. The conveyors are picked in view of the applications or procedures with mix of at least two conveyor composes as per the need. The kinds of conveyors are talked about one by one beneath.

Chute Conveyors: These conveyors are used for transporting Unit/Bulk materials with on-Floor orientation and accumulate products in the conveyor. This is a reasonable strategy and is utilized to interface two dealing with gadgets. It gives gathering in transportation territories and is additionally used to pass on things between floors. The main disadvantage of this system is that it is difficult to control position of the items on the conveyor [42].

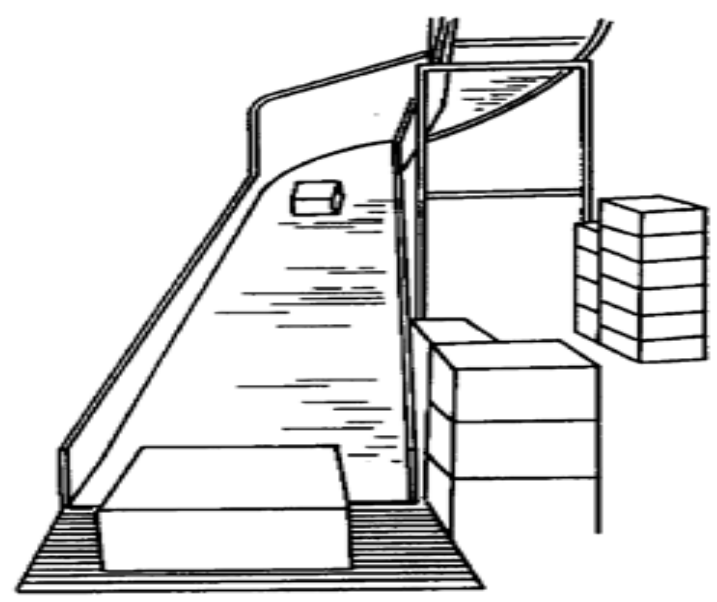

Fig. 5. Chute Conveyor system.

Wheel Conveyors: These conveyors are used for transporting unit supplies with on-floor orientation and allow products to accumulate in the conveyor. It uses a sequence of skate rolls astride over a shaft (or axle). Typography of the wheels is reliant on the cargo being conveyed. Slant for gravity drive depends on cargo mass. This method is more economical than the roller conveyor system. It's mostly used 
for mild-duty solicitations and it is stretchy, inflatable and itinerant varieties are also existing [42].
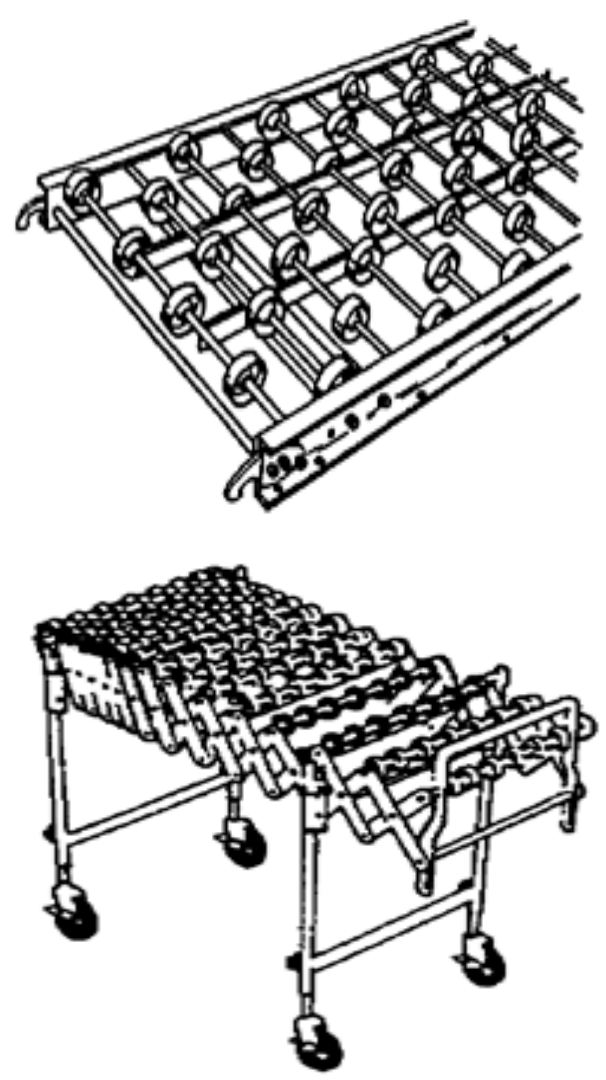

Fig. 6. Wheel Conveyor system

Roller Conveyor: These conveyors are used for transporting unit materials with on-floor orientation and allow products to accumulate in the conveyor. These conveyors may be powered (or live) or no powered (or gravity) and the supplies must have a rigid riding surface. These conveyors have a minutest of three rollers and must provision slightest heaps at all epochs. Tapering rollers on curves are used to retain cargo alignment. Parallel roller arrangement can be used as a (roller) pallet conveyor (extra lithe than a shackle pallet conveyor because rollers can be used to lodge are grander disparity of pallet girths).

Gravity roller conveyors are alternative to wheel conveyor systems and are used for tough tenders. Slant (i.e., decrease) for gravity development relies upon stack weight and this is for the most part utilized for aggregating loads. Live (fuelled) roller conveyor will be strap or shackle driven. Power delicate spread can be utilized to separate rollers for gathering. It is ordinarily utilized for gathering burdens and combining/arranging activities and it gives constrained slope development capacities [42].

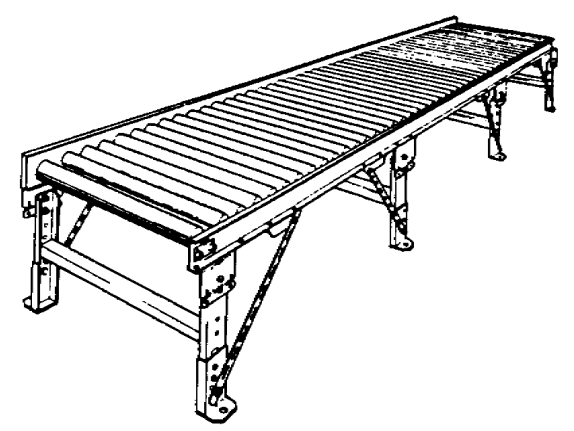

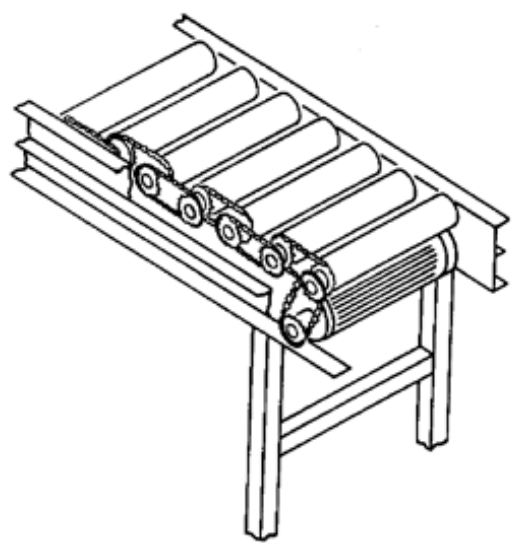

Fig. 7. Roller Conveyor system Gravity roller \& Live roller

Chain Conveyor: These conveyors are utilized for shipping piece supplies with in / on-floor orientation and do not allow products to accumulate in the conveyor. These frameworks utilize at least one unlimited chain over which loads are conveyed specifically. Parallel chain arrangement is utilized as (chain) bed transport or as a fly up gadget for sortation. Vertical chain transport is utilized for persistent highrecurrence vertical exchanges, where material on flat stages are joined to steel [42].

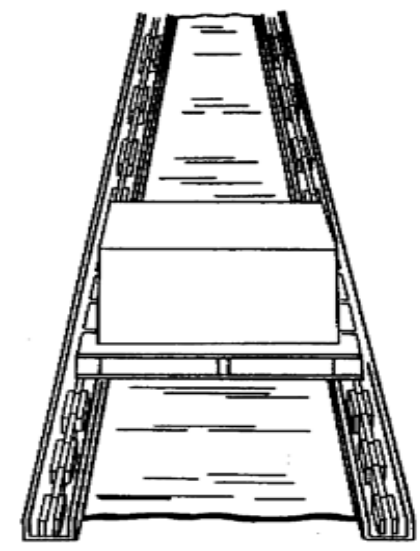

Fig. 8. Chain Conveyor system

Slat Conveyors: These conveyors are used for transporting unit materials with in / on-floor orientation and do not allow products to accumulate in the conveyor. It uses in isolation boards coupled to a shackle for transportation. The units which are being transported retains its position. The orientation and position of the load are controlled in this conveyor. This system is used for hefty heaps or heaps that might harm a strap of the conveyor system. Bottling and canning industries regularly utilize level chain or slat conveyors on account of clammy environments, hotness, and tidiness necessities. These slant slat conveyors are used for sortation of materials in industries [42].

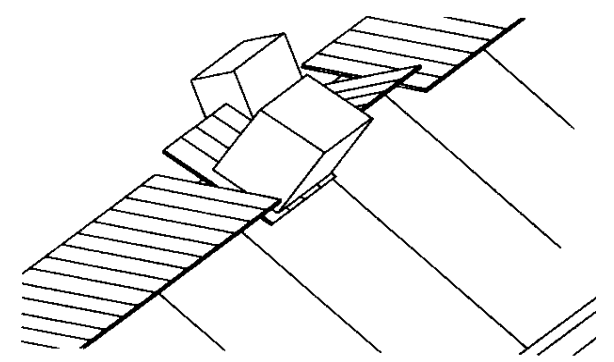

Fig. 9. Slat Conveyor system 
Flat Belt Conveyors: These conveyors are used for transporting unit materials with on-floor orientation and do not allow products to accumulate in the conveyor. It is used for transferring light and average mass materials between maneuvers, divisions, stages, and constructions. At the point when a slope or decay is required, it gives extensive control over the introduction and arrangement of materials. There is no even gathering, integration, and categorization on the strap and it is roller or slider bed support. The slider bed is used for minor and erratically shaped items to be transported [42].

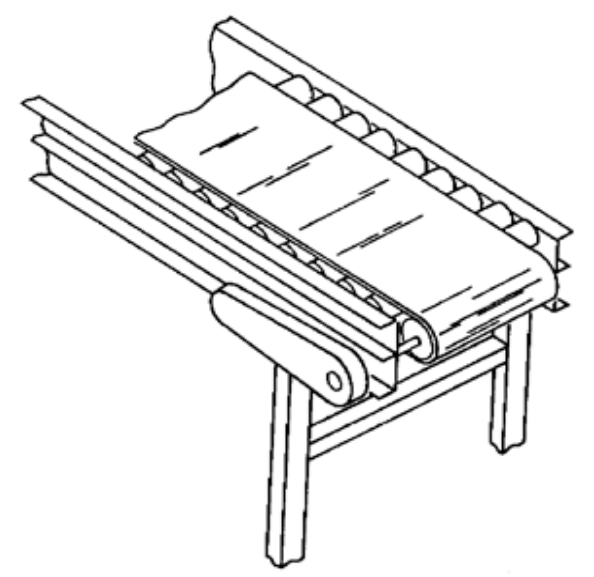

Fig. 10. Flat Belt Conveyor system

Magnetic Belt Conveyors: These conveyors are used for transporting bulk materials with on-floor orientation. A steel strap along with either an alluring slider bedstead or a magnetic winch is utilized to provide a magnetic belt. It is chiefly used to transference ferrous supplies steeply, topsyturvy, and about turnings of its establishment floor [42].

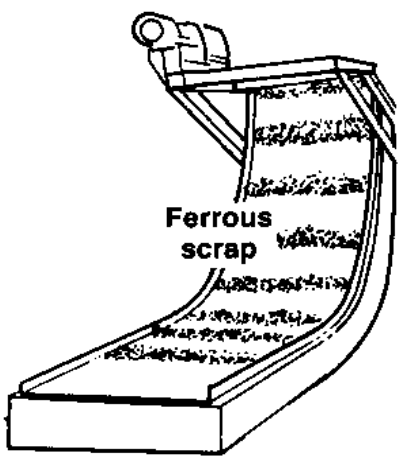

Fig. 11. Magnetic Belt Conveyor system

Troughed Belt Conveyors: These conveyors are used for transporting bulk materials with on-floor orientation. The belt looks flat and when it is burdened, the strap imitates to the silhouette of the troughed rollers and idlers. These are used in the transportation of coal blocks and limestone in cement industries [42].

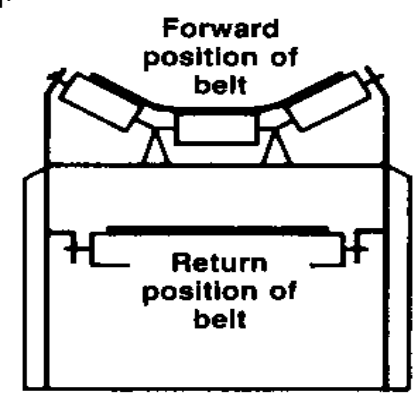

Fig. 12. Troughed Belt Conveyor system
Bucket Conveyors: These conveyors are used for transporting bulk materials with on-floor orientation. It is used to transfer wholesale supplies in an upright or inclined track with the help of bucket systems. Buckets are committed to a towline, shackle, or strap which will be running all along the path. Buckets are routinely unburdened at one end of the conveyor route and emptied automatically at the other end [42].

Fig. 13. Bucket Conveyor system

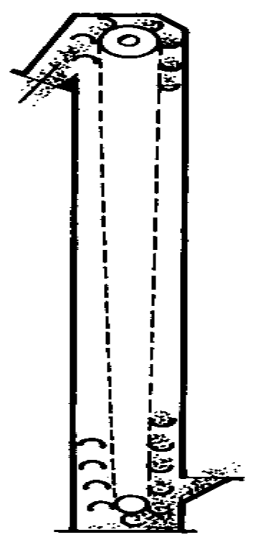

Vibrating Conveyors: These conveyors are also used for transporting bulk materials with on-floor orientation. The conveyor system involves a furrow, bed, or tube which quivers at a comparatively extraordinary frequency and trivial amplitude in order to deliver the vibration to distinct pieces of yields or bulk factual. This system can be utilized to transport practically all grainy, free-flowing supplies. The Vacillating Conveyor is comparable in development, however trembles at a minor recurrence and bigger amplitude (not as delicate) keeping in mind the end goal to pass on bigger objects, for example, hot castings, stone squares, and so on. Gold mines use vibrating conveyor for their sand cleaning process [42].

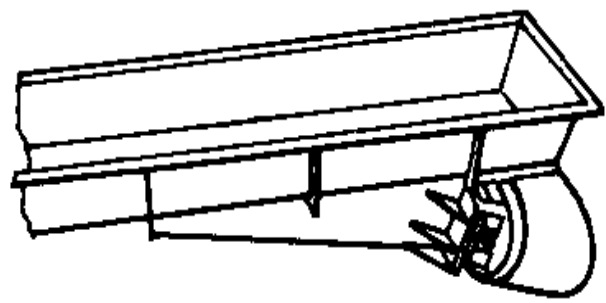

Fig. 14. Vibrating Conveyor system

Screw Conveyors: These conveyors are also used for shipping bulk constituents with on-floor orientation. This framework comprises of a cylinder or U-moulded immobile furrow over which a pole mounted helix rotates to drive free factual advancing in an even or slanted course. This is a standout amongst the most broadly utilized conveyors in the preparing business, with numerous applications in agrarian and synthetic handling. The straight-tube screw conveyor is also stated to as "auger feed". These are the most dominantly used in grains and cereals transportation [42].

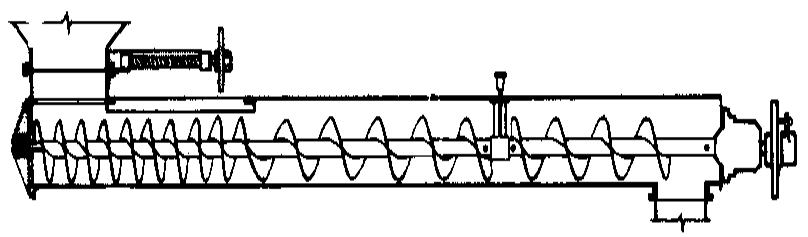

Fig. 15. Screw Conveyor system 
Pneumatic Conveyors: These conveyors are also used for transporting bulk and unit materials with overhead orientation. This system uses air pressure to transport supplies over a scheme of erect and flat tubes. Factual is totally encased and it is anything but difficult to execute turns and erect moves in this shut framework. There are two types of pneumatic conveyor systems and they are (i) Dilute-phase pneumatic conveyor and (ii) Carrier-system pneumatic conveyor. Here Dilute-stage pneumatic conveyor uses a blend of air and rock-solid. Thrust (progressive pressure) frameworks push the factual starting from one section point to a few release focuses. Pull (negative pressure or vacuum) frameworks moves the material from a few passages focuses to one release point. Push-pull frameworks are blends with numerous passage and release focuses which are broadly utilized as a part of a system of transports in ventures. Carriersystem pneumatic conveyor utilizes a carrier medium to transport material from one end to the other. These carriers are utilized to transference items or paperwork. Transportation of oil by pumping water as the carrier is one of the examples [42].
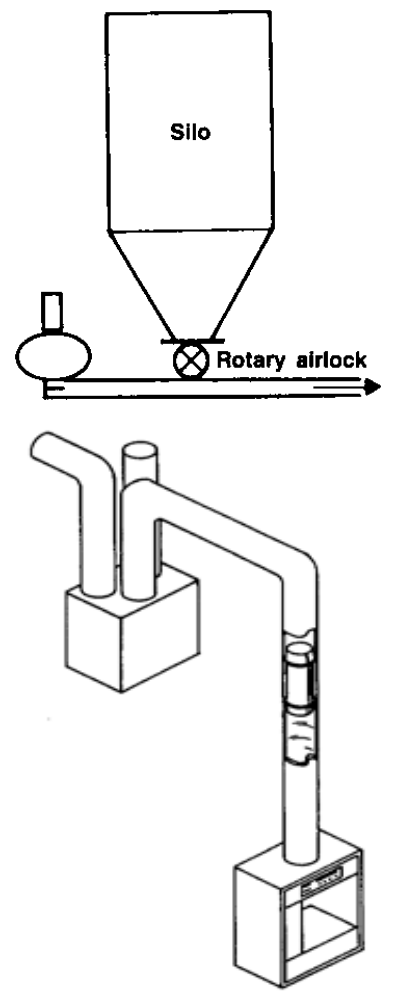

Fig. 16. Pneumatic Conveyor system dilute phase and Carrier system

Vertical Conveyors: These conveyors are also used for transporting unit materials with on-floor orientation and do not allow products to accumulate in the conveyor. These frameworks are utilized for low-recurrence irregular vertical exchanges of load to various floors as well as mezzanines. In any case, upright shackle conveyors can be utilized for nonstop high-recurrence upright exchanges. It fluctuates from the carriage elevators in such a way that it is not planned or specialized to transfer individuals. It can be physically or robotically burdened or well-ordered and can interface with level conveyors also. It is a substitute to chute conveyor for upright "drops" when cargo is brittle and/or space is restricted. There are two sorts of vertical conveyors (i) Vertical lift conveyors (ii) Reciprocating Vertical Conveyors. In vertical lift conveyors, a progression of adaptable conveyor bearers turns in a circle, where void carters flex vertically to give admission to stacked carters moving past them the inverse way. In reciprocating upright conveyor, a carter is utilized to elevate or subordinate the masses. It can be fuelled (hydraulic or mechanical) or non-fuelled conveyor line. The non-fuelled version can be used only to subordinate a cargo, where counterbalance is used to return vacant carter to the topmost [42].

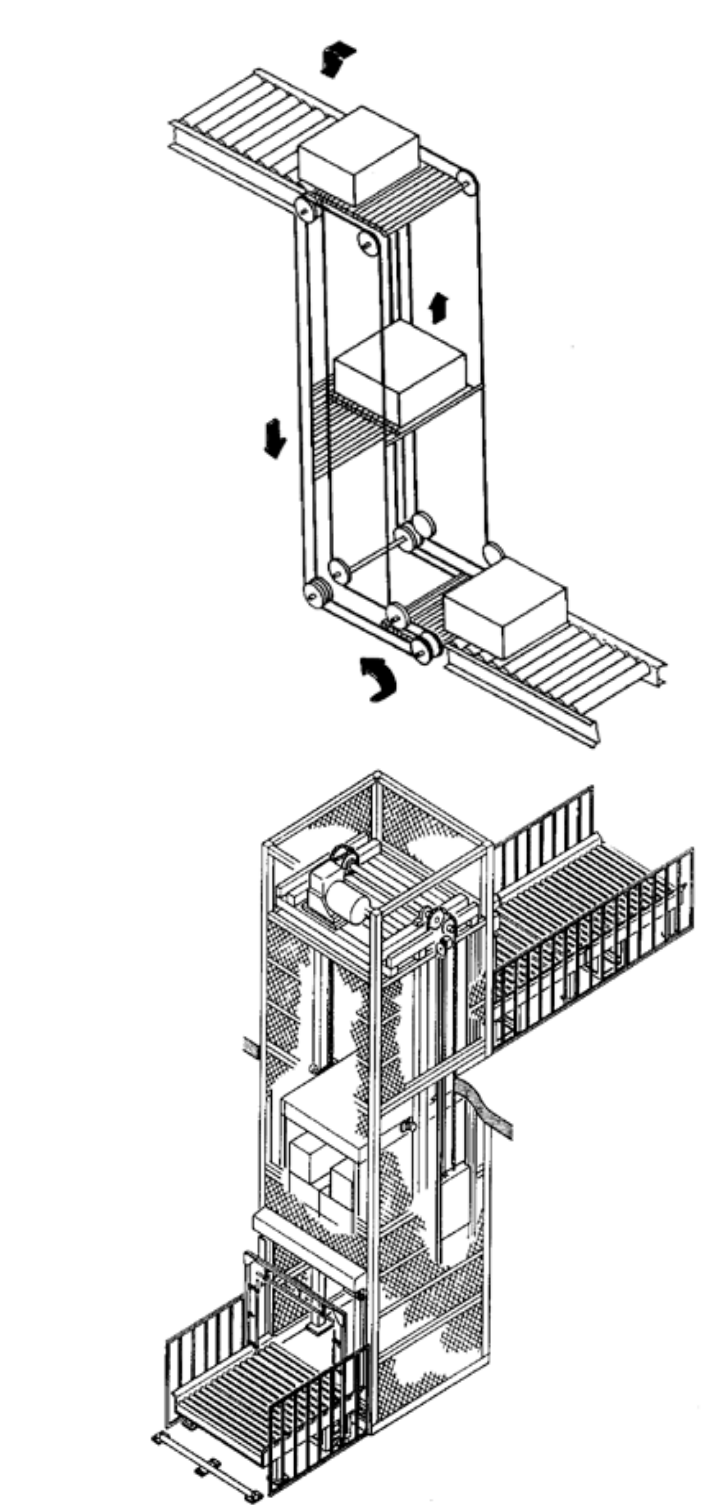

Fig. 17. Vertical Conveyor system - Vertical lift and Reciprocating vertical conveyor

Cart - On - Track Conveyors: These conveyors are also used for transporting unit materials with in-floor orientation and allows products to accumulate in the conveyor. It is utilized to transference carts alongside a pathway. The carts are conveyed by a spinning cylinder to which a drive wheel is linked to each cart. The cart respites on the tube and is used to differ the hustle of the cart (by fluctuating angle of contact among drive wheel and the cylinder). These wagons are autonomously well-ordered and collection can be accomplished by keeping up the drive wheel comparable to the cylinder [42]. 


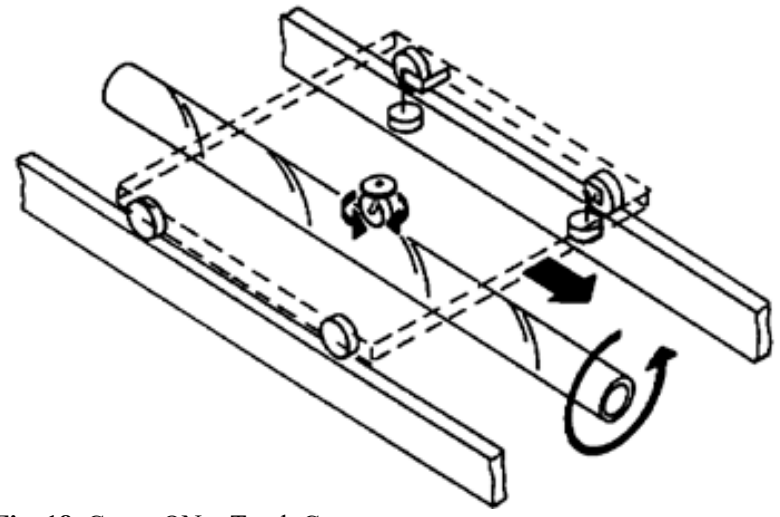

Fig. 18. Cart - ON - Track Conveyor system

Tow Conveyors: These conveyors are also used for transporting unit materials with in-floor orientation and allows products to accumulate in the conveyor. It uses a towrope to afford power to wheeled carters such as wagons, dollies, or carts that travel beside the ground. It is used for a fixed-path travel of carters (each has fickle pathway competences when detached from towrope) only. The towrope is typically on the floor or it can be positioned overhead or blush with the floor. The selector-pin or pusherdog plans used to permit programmed exchanging (power or limb lines). It is, for the most part, utilized when a long separation and high recurrence moves are required [42].

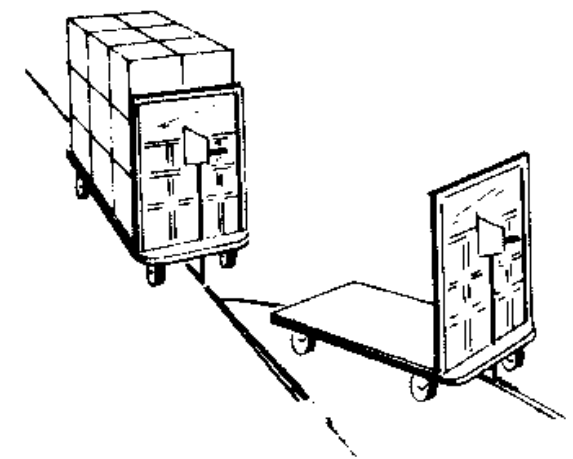

Fig. 19. Tow Conveyor system

Trolley Conveyors: These conveyors are also used for transporting unit materials with overhead orientation and do not allow products to accumulate in the conveyor. It utilizes a progression of trolleys upheld from or inside an overhead pathway. The trolleys are similarly separated in an enclosed circle way and are on hold from a shackle. The shippers are used to transfer numerous units of merchandise and do not provide any provision for accretion of units. It is universally used in dispensation, assemblage, wrapping, and storing operation applications [42].

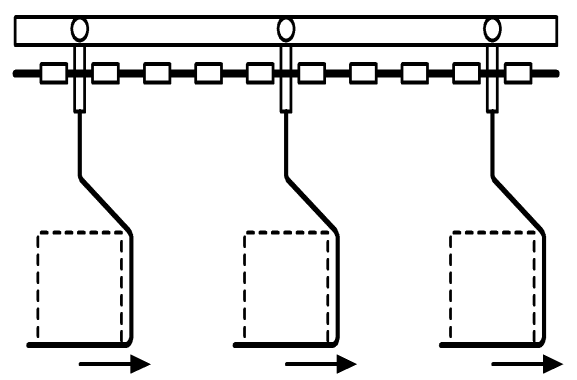

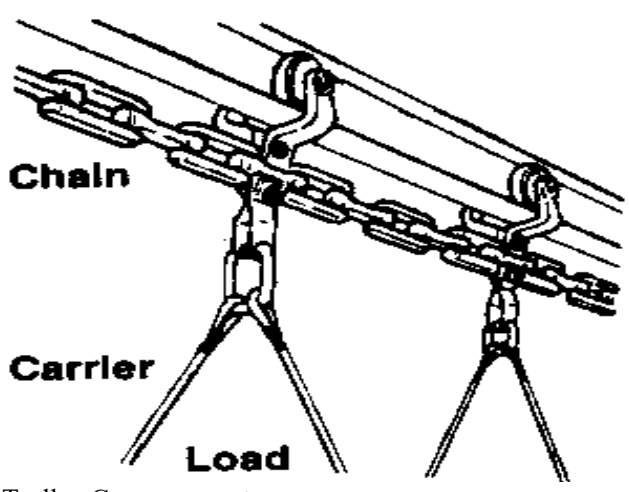

Fig. 20. Trolley Conveyor system

Power And Free Conveyors: These conveyors are also used for transporting unit materials with overhead or on-floor orientation and allows products to accumulate in the conveyor. It is also termed as Inverted Power-and-Free Conveyor when pathways are positioned on the floor. It is like trolley conveyor because of utilization of discretely divided bearers transported by an overhead chain. However, these conveyors utilize two trails: one powered and further nonpowered. The carters can be withdrawn from the power shackle and aggregated or exchanged onto subdivisions [42].
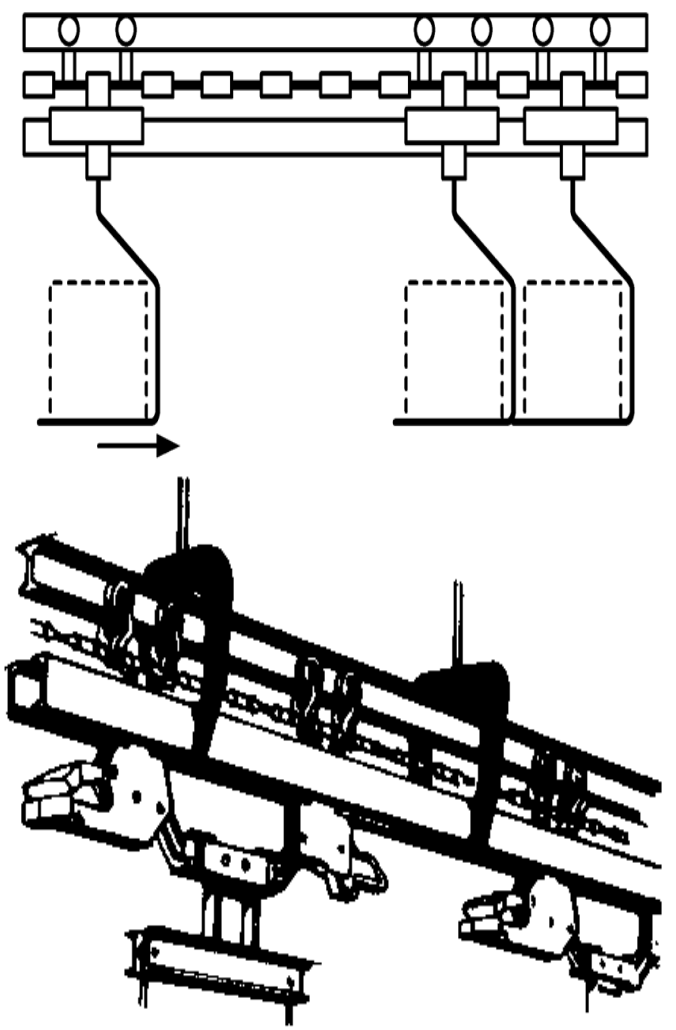

Fig. 21. Power and free Conveyor system

Monorail: These conveyors are also used for transporting unit materials with overhead orientation and allows products to accumulate in the conveyor. It comprises of an overhead single pathway (i.e., mono-rail) or track grid over which at least one carriers ride. These carriers might be controlled (electrically or pneumatically) or non-fuelled ones. The carrier can range from a simple hanger to a winch to an intelligent-vehicle-like device. There are two types of monorails (i) Single Carrier (ii) Multi-carrier. The singlecarrier type has a single-track monorail similar to bridge or gantry crane. The multi-carrier compose has a track organized 
monorail like a trolley conveyor, aside from that the carriers work autonomously and the trail require not be in an enclosed circle, and a settled way programmed guided vehicle (PGV or AGV) framework, with the exception of that it works overhead. It is additionally named as an Automated Electrified Monorail (AEM) framework when it has comparable control qualities as an AGV framework [42].

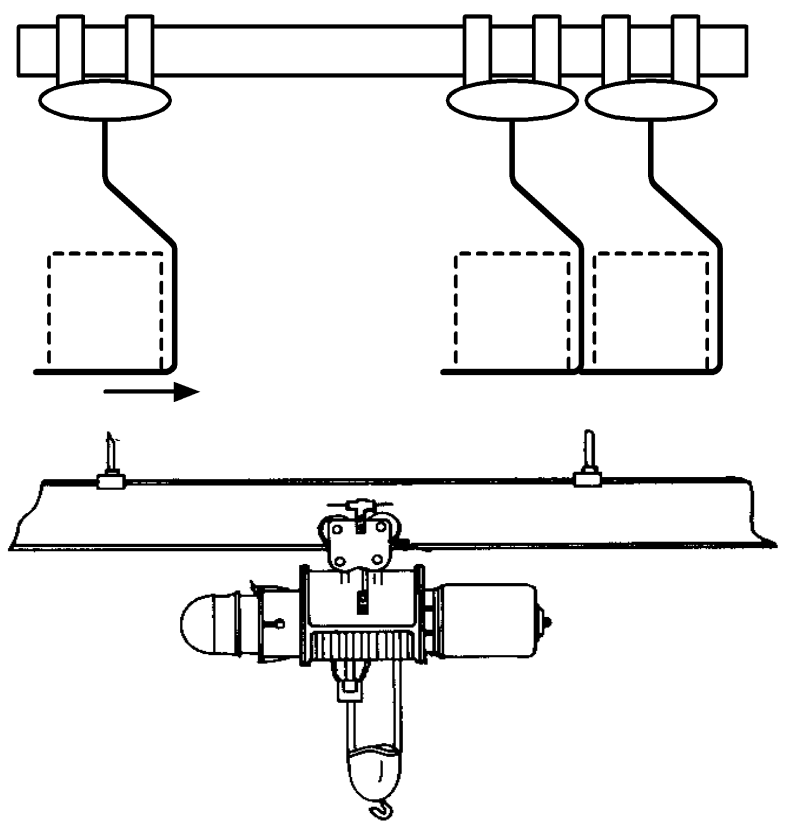

Fig. 22. Monorail system

Sortation Conveyor: These conveyors are also used for transporting unit materials with overhead or on-floor orientation. The sortation conveyors are utilized for consolidating, distinguishing, drafting, and isolating items to be passed on to particular terminuses. Sortation framework factual output is communicated in cartons per moment or minute (CPM). A sortation framework is made out of three subsystems:

Merge subsystem - Here the things are transported from picking (stockpiling) or getting regions on transports and merged for legitimate introduction at the induct zone.

Induct subsystem - Here the goal of everything is distinguished by visual assessment or programmed recognition framework (e.g., standardized tag scanner) and afterward an appropriate gap between things is produced utilizing petite adjustable swift conveyors as they are discharged to the sort subsystem.

Sort subsystem - In this system the things are redirected to outbound conveyors to transportation, palletizing, organizing, as well as auxiliary sort subsystems.

There is a pattern towards more utilization of blended thing heaps that take out the requirement for sortation: rather than a maker directing pallet heaps of a solitary thing to a dissemination community for consequent sortation or combination into multi-thing client heaps, lone pallets can be stacked at a maker with an alternate blend of things for every client. This additionally can empower more prominent utilization of cross-docking. There are five different types of sortation conveyors and are (i) Diverters (ii) Pop up expedients (iii) Sliding shoe sorter (iv) Tilting Expedient (v) Cross belt transfer expedient.

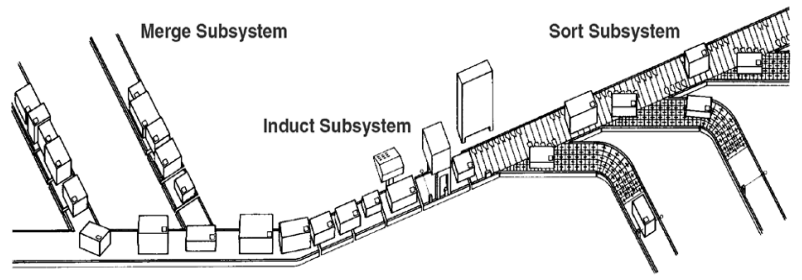

Fig. 23. Sortation Conveyor system

Diverters have motionless or portable arms that bounce, shove, or tug a merchandise to the chosen terminus. As they do not come in interaction with the conveyor, they can be utilized with almost any horizontal surface conveyor. They are hydraulically or pneumatically functioned, and also can be motor operated. There are two types of diverters (i) Deflector Diverters (ii) Push Diverters. The main advantage is that it is simple and low cost.
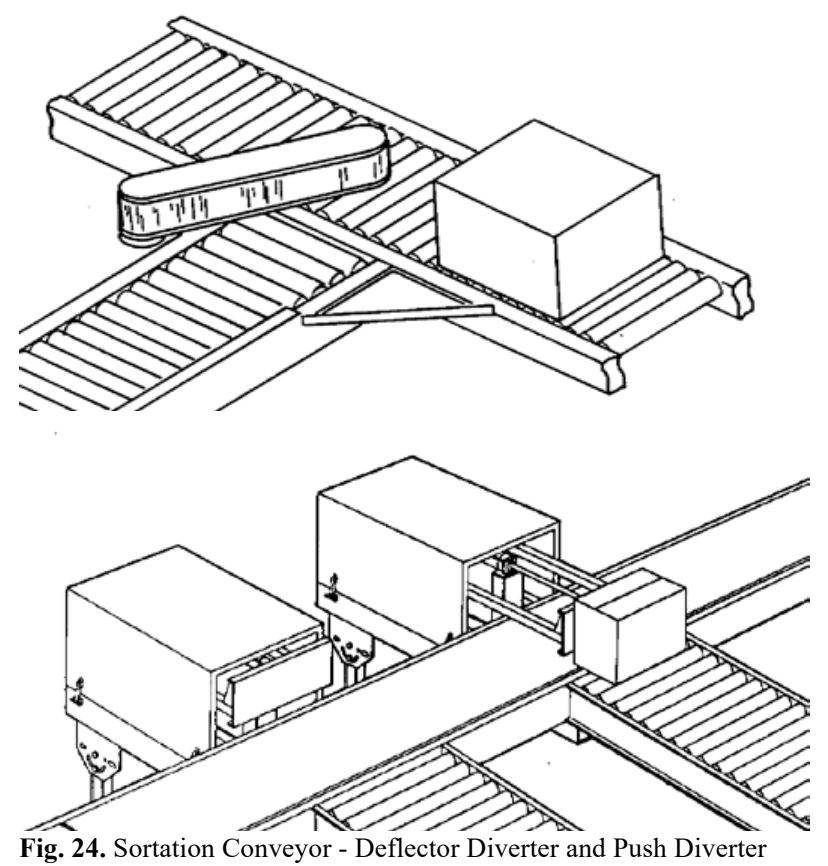

Pop up devices are at least one or more lines of powered rollers or wheels or shackles that hop over the surface of the conveyor to lift the thing and guide it off the conveyor at a fitting point. The wheels will be dropped when merchandises not mandatory to be side-tracked. This system is proficient of sorting flat-bottomed matters and are usually more rapid than pop-up wheels.

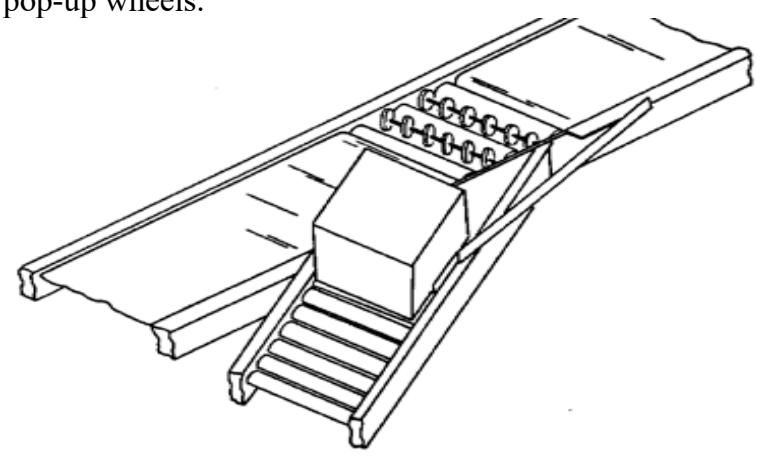




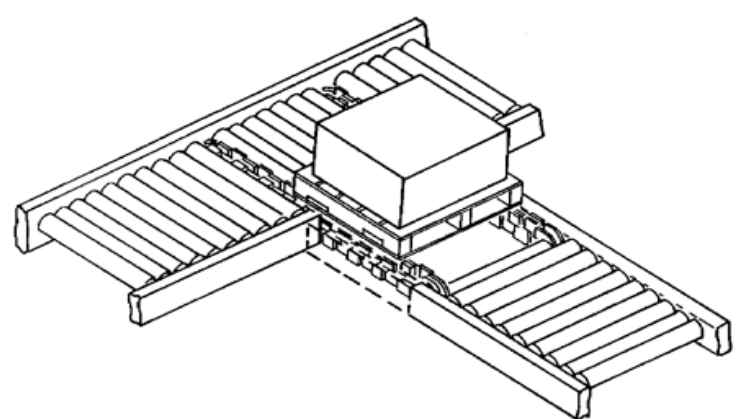

Fig. 25. Sortation Conveyor - Pop up wheel device and pop up chain device

Sliding shoe sorter which is also known as moving slat sorter uses a sequence of diverter slats that slide across the flat surface to occupy product to guide it off the conveyor. The slats move from side to side as item streams keeping in mind the end goal to redirect the item to either side. It is for delicate and progressive treatment of items.

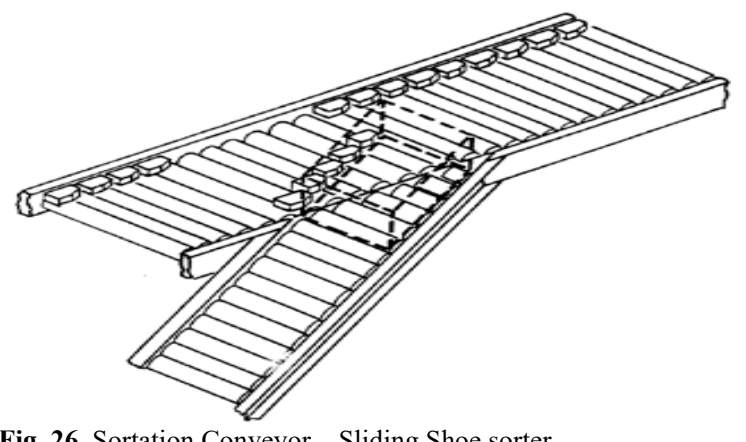

Fig. 26. Sortation Conveyor - Sliding Shoe sorter

Tilting devices use trays or slats which provide collective sorting appliance and product transporter. It can suit height changes and are normally outlined in persistent loops with minimized format or layouts and the distribution of items are not arranged in the first run through. Tilt slat sorters convey items on level surface slat conveyor and can deal with more extensive assortment of items when contrasted with tilt tray.

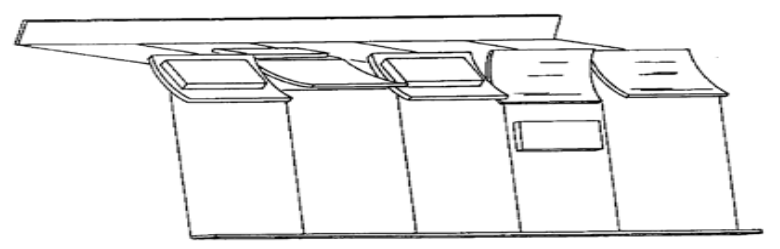

Fig. 27. Sortation Conveyor - Tilting Tray Device

Cross-belt exchange gadget has either constant loops where each and every individual carriage are connected together to shape an interminable loop, or a series style belt (asynchronous), where few carriers integrated with potential for a few trains running track at the same time. Every carriage is furnished with a small belt conveyor, named the cell, which is mounted perpendicular to the bearing of movement of the loop and releases the item at suitable places. It naturally isolates a single line of items into different in-line release lines [42].

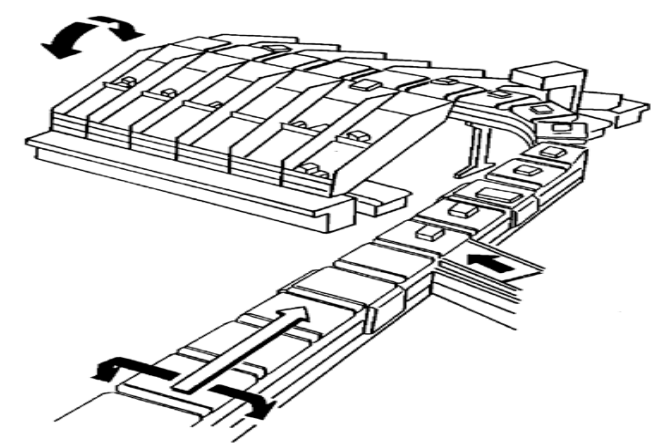

Fig. 28. Sortation Conveyor - Cross belt transfer device

The table indicating the advantages and applications of these conveyor systems are given below,

Table 1. Advantages \& Applications of conveyor systems.

\begin{tabular}{|c|c|c|c|}
\hline S.No & Conveyor Type & Advantage & Application \\
\hline 1. & Chute Conveyors & Can transport unit/bulk materials & $\begin{array}{l}\text { Packing sectors of scraps, cement bags, postal } \\
\text { packages, etc. }\end{array}$ \\
\hline 2. & Wheel Conveyors & $\begin{array}{l}\text { Unpowered wheels are used } \\
\text { Orientation can be altered based on } \\
\text { requirement }\end{array}$ & $\begin{array}{l}\text { Loading \& Unloading operations in trucks, } \\
\text { finished product handling in packing sectors, } \\
\text { etc. }\end{array}$ \\
\hline 3. & Roller Conveyors & $\begin{array}{l}\text { Can be powered or unpowered based on } \\
\text { requirement } \\
\text { Used for rigid object transportation }\end{array}$ & $\begin{array}{l}\text { Utilized in baggage handling, loading and } \\
\text { unloading sectors, instrument assembly paths, } \\
\text { etc. }\end{array}$ \\
\hline 4. & Chain Conveyors & Chains enhance the speed of conveyance & $\begin{array}{l}\text { Utilized in systems with many discharge } \\
\text { vents, industrial baskets, etc }\end{array}$ \\
\hline 5. & Slat Conveyors & $\begin{array}{l}\text { Flexibility in position \& orientation is the } \\
\text { main feature of the conveyor }\end{array}$ & $\begin{array}{l}\text { Used for heavy loads, oily parts in dryers, } \\
\text { bottling \& canning processes, etc }\end{array}$ \\
\hline 6. & Flat Belt Conveyors & $\begin{array}{l}\text { Longer life with lower power consumption. } \\
\text { Highly reliable and adaptable }\end{array}$ & $\begin{array}{l}\text { Raw material supply unit in industries, Wheel } \\
\text { excavators, Harbours, Bakeries \& flour mills, } \\
\text { etc. }\end{array}$ \\
\hline 7. & $\begin{array}{l}\text { Magnetic Belt } \\
\text { Conveyors }\end{array}$ & $\begin{array}{l}\text { Least maintenance required } \\
\text { Longer life using strong magnets and SS } \\
\text { plates. }\end{array}$ & $\begin{array}{l}\text { Metal Cutters, conveyance of metallic parts } \\
\text { and stampings, etc }\end{array}$ \\
\hline 8. & $\begin{array}{l}\text { Troughed Belt } \\
\text { Conveyors }\end{array}$ & $\begin{array}{l}\text { Problem causing materials can be conveyed } \\
\text { with higher capacities. } \\
\text { Lightest form of conveying with minimum } \\
\text { labour requirement. }\end{array}$ & $\begin{array}{l}\text { Can be used for conveying all sort of } \\
\text { materials like wet, dry, oily, sticky, etc. } \\
\text { Used for underground mine transport. }\end{array}$ \\
\hline 9. & Bucket Conveyors & $\begin{array}{l}\text { Can be used with different shapes and sizes. } \\
\text { Can be used in all kinds of environmental } \\
\text { conditions }\end{array}$ & $\begin{array}{l}\text { Used in mining, oil mills, construction works, } \\
\text { etc }\end{array}$ \\
\hline
\end{tabular}




\begin{tabular}{|c|c|c|c|}
\hline \multirow{3}{*}{10.} & \multirow{3}{*}{ Vibrating Conveyors } & \multirow{3}{*}{$\begin{array}{l}\text { Can be utilized for conveying different kind } \\
\text { of materials without mixing to a longer } \\
\text { distance. } \\
\text { Supplementary processes like heating, } \\
\text { dehydrating, chilling, etc can be performed } \\
\text { along with conveying. }\end{array}$} & \multirow{3}{*}{$\begin{array}{l}\text { Can be used as feeder, spreader, extractor, } \\
\text { grizzly, segregation of materials, recycling } \\
\text { process, etc. }\end{array}$} \\
\hline & & & \\
\hline & & & \\
\hline 11. & Screw Conveyors & $\begin{array}{l}\text { Can convey bulk materials with multiple } \\
\text { inlet \& discharge points with gates and }\end{array}$ & $\begin{array}{l}\text { Used for conveying wet biosolids and sticky } \\
\text { sludges. }\end{array}$ \\
\hline & & $\begin{array}{l}\text { valves. } \\
\text { These are compact and adaptable. }\end{array}$ & $\begin{array}{l}\text { Forms a major part of conveying in food, } \\
\text { chemical, wood and minerals industries. }\end{array}$ \\
\hline 12. & Pneumatic Conveyors & $\begin{array}{l}\text { Requires lower maintenance and has more } \\
\text { flexibility. } \\
\text { Requires lesser energy for operation \& is } \\
\text { safer. }\end{array}$ & $\begin{array}{l}\text { These conveyors are used in industries like } \\
\text { food, agriculture, pharmaceutical, cement, } \\
\text { plastic, etc. }\end{array}$ \\
\hline 13. & Vertical Conveyors & $\begin{array}{l}\text { These are flexible and modular and can be } \\
\text { altered based on need. } \\
\text { Reciprocal vertical conveyors utilize the } \\
\text { gravitational pull which reduces the power } \\
\text { requirement. }\end{array}$ & $\begin{array}{l}\text { These systems are used in lifting operations, } \\
\text { car parking systems, material transport to } \\
\text { various floors, etc. }\end{array}$ \\
\hline 14. & $\begin{array}{l}\text { Cart-On-Track } \\
\text { Conveyors }\end{array}$ & $\begin{array}{l}\text { These are simple and shorter length } \\
\text { conveyors. } \\
\text { They are adjustable and reliable. }\end{array}$ & $\begin{array}{l}\text { These are used in automobile parking systems, } \\
\text { airport luggage carriers, various assembly } \\
\text { lines, etc. }\end{array}$ \\
\hline 15. & Tow Conveyors & $\begin{array}{l}\text { These systems are more flexible, reliable and } \\
\text { customizable. } \\
\text { It is easy to integrate these systems with the } \\
\text { prevailing systems. }\end{array}$ & $\begin{array}{l}\text { Towline conveyors are widely used in aircraft } \\
\text { \& engine assembly lines, wind turbine } \\
\text { assembly lines, furniture and apparel } \\
\text { handling, agricultural equipment handling, } \\
\text { etc. }\end{array}$ \\
\hline 16. & Trolley Conveyors & $\begin{array}{l}\text { It is more flexible and modular. } \\
\text { More designs are available for various } \\
\text { applications }\end{array}$ & $\begin{array}{l}\text { It is most popularly used in assembly and } \\
\text { packaging section of automobile industries, } \\
\text { storage lines in food industries, etc. }\end{array}$ \\
\hline 17. & $\begin{array}{l}\text { Power and Free } \\
\text { Conveyors }\end{array}$ & $\begin{array}{l}\text { Normally uses high strength alloy castings } \\
\text { which gives modular design, increased life } \\
\text { span, compact and simple. }\end{array}$ & $\begin{array}{l}\text { Most frequently used in elevation changing } \\
\text { applications, transferring materials, assembly } \\
\text { sectors, sorting units, etc. }\end{array}$ \\
\hline 18. & Monorail & $\begin{array}{l}\text { These are noiseless and fast transport } \\
\text { systems. } \\
\text { Its highly available with lower investments. }\end{array}$ & $\begin{array}{l}\text { These are widely used in winches, rope cars, } \\
\text { assembly and packing sectors in automobile } \\
\text { industries, etc. }\end{array}$ \\
\hline 19. & Sortation Conveyors & $\begin{array}{l}\text { They can be operated using hydraulic and } \\
\text { pneumatic lines. } \\
\text { Cost effective and simple with wide range of } \\
\text { operations. }\end{array}$ & $\begin{array}{l}\text { These are used in sorting materials for } \\
\text { recycling, baggage in airports, merging } \\
\text { systems, etc. }\end{array}$ \\
\hline
\end{tabular}

\section{Thermography \& Its Types}

Basically, thermography is classified into two types (i) Passive Thermography and (ii) Active Thermography.

Passive thermography has passive tests which involve steady-state conditions. It does not require any external heating or cooling. It is commonly applied to asses or monitor the state of industrial processes. This method is simple and cost-effective and does not require any physical contact (No interaction with the specimen). For passive thermography dual wavelength camera is more advantageous but it will work only if the thermal contrast is naturally present. Passive thermography finds its applications in carton sealing line examination, vehicle brake system effectiveness, heat dissipation in electronic components, welding process, steam traps, refractory linings, electric installation, gas leaks, bearings, moisture in roofs and walls, etc.

Active thermography is further classified into six types and they are (i) Pulsed thermography, (ii) Pulsed phase thermography, (iii) Lockin thermography with optical excitation, (iv) Lockin thermography with ultrasonic excitation, (v) Step heating thermography, (vi) Vibro thermography

Pulsed thermography is the utmost widespread active thermography method. It is fast and quick and uses short pulse for high conductivity material and a long pulse for low conductivity material. It consists of briefly heating the specimen by using flash heating and observe the decay curve. The observation time is directly proportional to the square of the depth of the discontinuity and inversely proportional to the thermal diffusivity. Loss of contrast is inversely proportional to the cube of the decay depth.

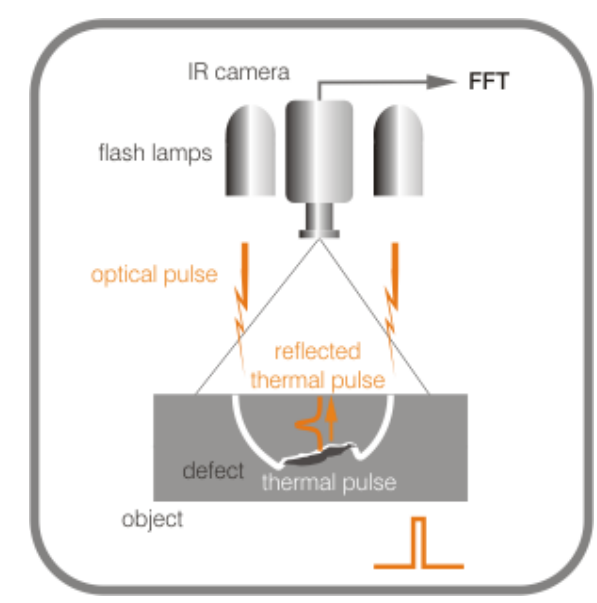




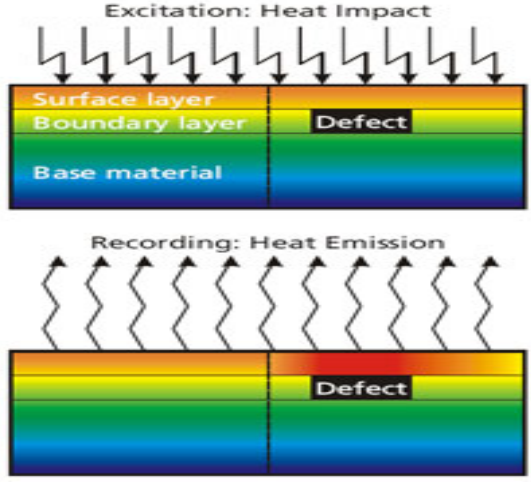

Fig. 29. Pulse thermography by optical excitation and defect detection

Noticeable cut-offs are usually shallow and weak in pulse thermography. A thumb rule of pulsed thermography is that the radius of the minutest noticeable disjointedness should be at least two times bigger than its depth beneath the surface. Heating methods used in pulse thermography are point heating, line heating, and surface heating. Point heating uses laser or the focused light beam for heating. The main advantage of pulsed thermography is the uniform and repeated heating but the disadvantage is, it's a slow process. Line heating involves the heating by the line lamps, heated wire, scanning laser, Hot or cold air jets, etc. Surface Heating uses lamps, flash lamps or scanning laser. Its advantages are a complete analysis of the phenomena because the whole temperature history curve is recorded but the disadvantage is anisotropy of heating by lamps, flash, heat gun, and laser. There are two basic arrangements for observation: Reflection approach and transmission approach. So, the advantage of pulsed thermography is its quick response and drawback is its limited resolution both in depth and spatial area. The contrast generated for all of the discontinuity depth curves is lower for smaller discontinuities than for larger discontinuities. The rate of contrast decay (as the discontinuities move deeper through the thickness) is higher for the smaller discontinuities. The widths of the contrast peaks are narrower for the smaller discontinuities. The narrow peaks indicate that the thermal indications will not persist long in the thermal images. The biggest drawback of pulse thermography is that only a part of the temperature history curve is available because of the lateral motion and it requires apparatus to induce pulsed thermal perturbation. Computation of thermal contrast requires prior knowledge of defect-free zone in the field of view and the inspection surface is limited ( $\left.0.25 \mathrm{M}^{2} \mathrm{Max}\right)$. Some of the applications of pulsed thermography are in process control, discontinuity detection, delamination detection, material characterization, etc.

Lockin thermography is based on thermal waves produced inside the examined sample and perceived distantly. The word lockin mentions to the inevitability to observe the exact time requirement of the heating, modulated between the output indication and the reference input indication. The term lockin thermography relates to the device that usually performs the same analysis of signals with respect to a reference frequency. Lockin thermography is also called photothermic radiometry and a type of phase sensitive modulation thermography. Compared to conventional photothermal radiometry this technique may be considered as spatially multiplexed photothermal radiometry because the whole sample surface is monitored during one cycle. This is prepared with a lockin amplifier by a point-by-point laser heating or by mainframe in full field arrangement so that both phase and magnitude imageries become accessible. Wave generation, for example, is achieved by periodically dumping heat on the sample surface (for example, through sine modulated lamp heating) while the resultant wavering temperature field in the motionless regime is distantly logged through its thermal infrared emanation. In lockin thermography, the specimen is subjected to a sinusoidal thermal stimulation. The temperature evolution of the surface is also measured using an infrared camera but in the steady state.

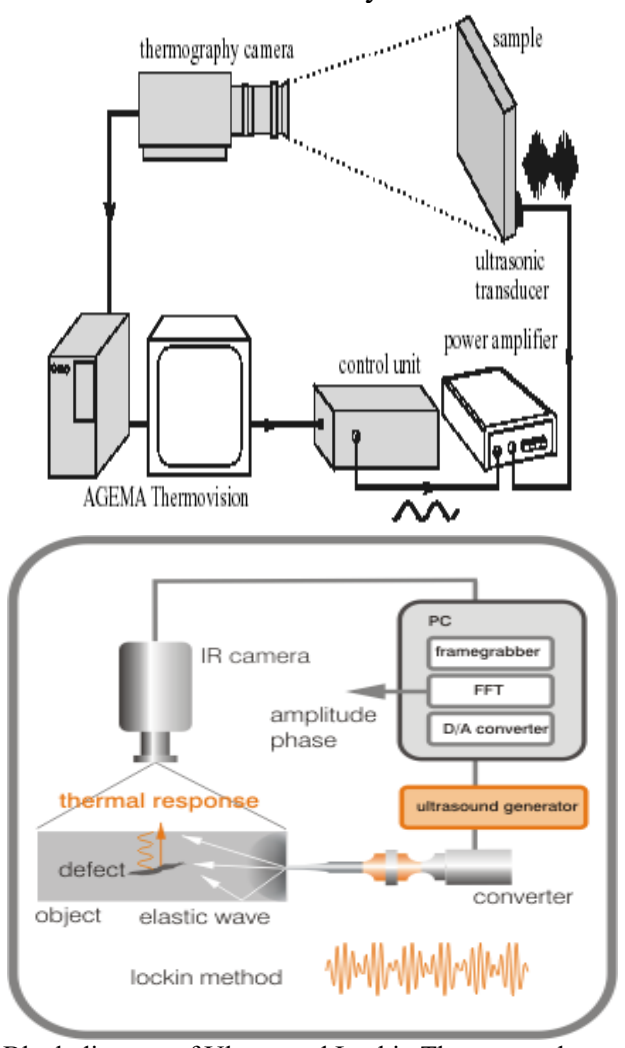

Fig. 30. Block diagram of Ultrasound Lockin Thermography

In Lockin thermography usually, test object is irradiated by an intensity modulated lamp. So the image contains both discontinuity and intact structure (background) so it has to be compared to a reference sample to evaluate the discontinuities. Again internally generated thermal waves travel half the distance involved in surface heating, so there are less attenuation and better resolution. The phase angle is proportional to the depth of the discontinuity (i.e. the depth of the source under the surface). Again, this technique is more economical since only the discontinuity is heated and not the whole component. This method is like dark field technique in optics. So, the internally generated thermal wave produces only the discontinuity indication in the image.

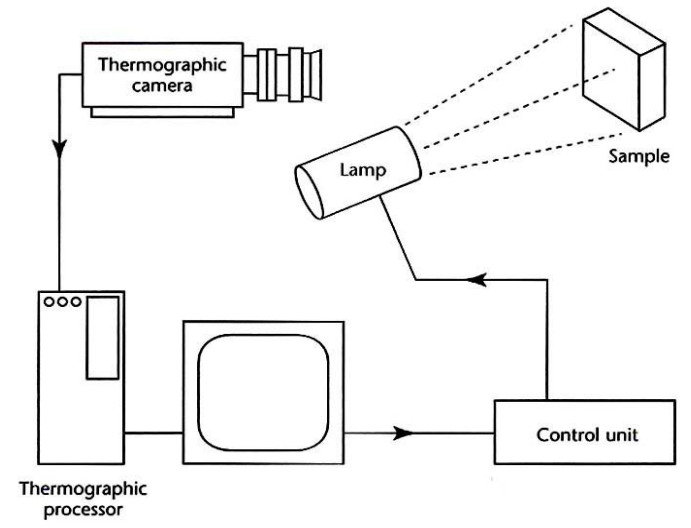




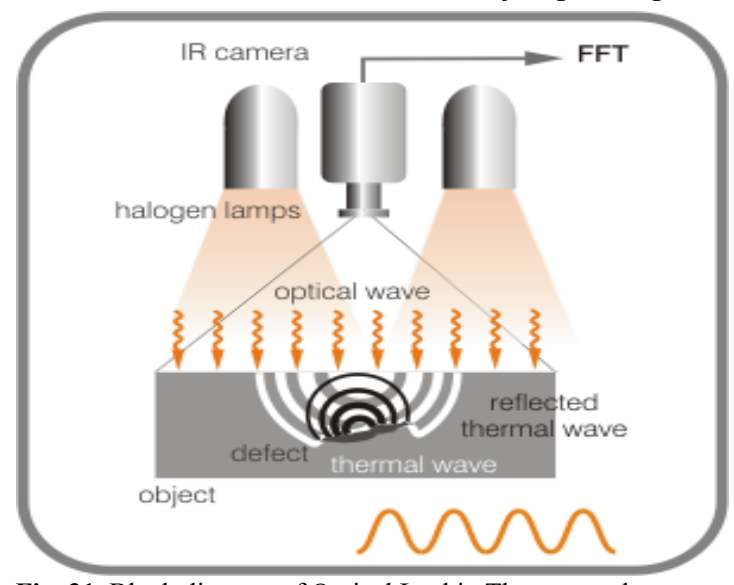

Fig. 31. Block diagram of Optical Lockin Thermography

In optical Lockin Thermography, thermal waves are sensitive to boundaries from which they are reflected according to the mismatch of thermal impedance. Therefore lockin thermography with optical excitation ("OLT" = optical lockin thermography) is applicable to non-destructive evaluation of components where boundaries or their integrity need to be monitored, e.g., layered materials, Coatings (Interest in coatings is the thickness and the detection of local disbands), paints, veneered wood and ceramic coating on metal; .If the substrate in the paint coating is a polymer and if substrate and coatings are similar then capacitive or inductive or ECT etc cannot be applied.
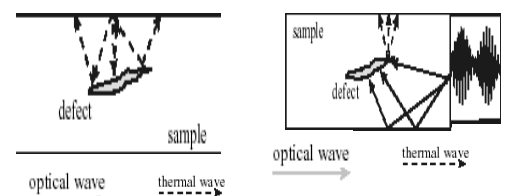

Fig. 32. Comparison of Optical Lockin Thermography vs Ultrasound Lockin Thermography

The figure in the left shows Optical excitation as used in optical lockin thermography. Superposition of incoming and outgoing thermal wave results in a limited penetration depth. The figure in the right shows Ultrasound excitation generates thermal waves in the defect itself, maximum depth range is only noise limited and therefore basically larger than with optical excitation.

Ultrasound Burst Phase thermography is mostly used in automobile industries for crack detection, characterization of shrink fits or press fits, adhesively bonded joints, artificial defects, non-cured adhesion, etc.

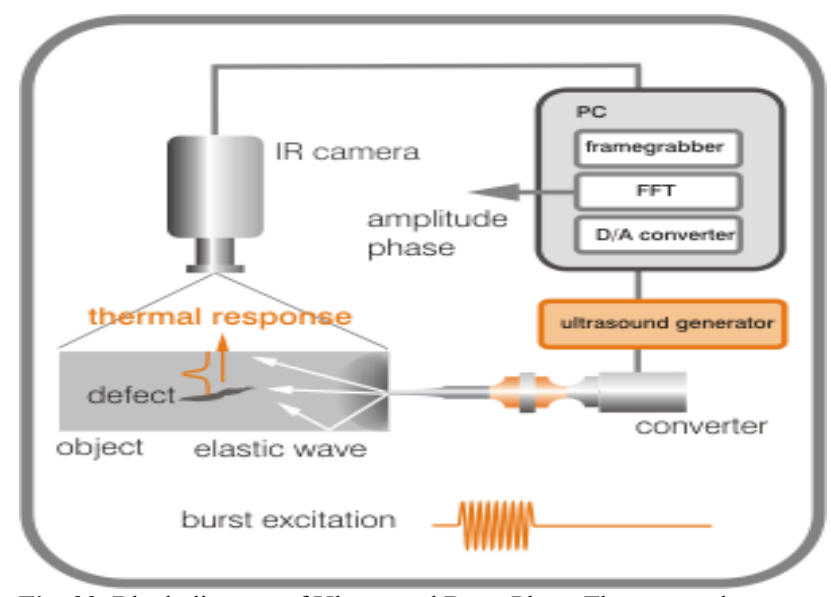

Fig. 33. Block diagram of Ultrasound Burst Phase Thermography
Sometimes other stimulations are possible in lockin thermography. For illustration, an ultrasound transducer (shaker) can be connected to the sample, or the specimen can be partly immersed in an ultrasonic pool. In these cases, the high-frequency ultrasonic signal (typically about $40 \mathrm{kHz}$ ) is modulated with a low-frequency signal. The low-frequency modulation produces a thermal wave of required wavelength as in photothermal lockin thermography while the high frequency acts as carrier delivering heating energy inside the specimen. This technique is referred to as the loss angle lockin thermography and has been applied with success for detection of corrosion, vertical cracks and delamination. Lockin thermography combines the advantages of photothermal radiometry (phase information and adjustable depth range) and thermography (speed of imaging and ease of operation) but avoids their specific disadvantages. These angle images with application relevant depth range are obtained within typically $3 \mathrm{~min}$ where the modulation technique eliminates sensitivity to artifacts. Therefore, the technique is applicable for industrial tests even under rough conditions.

Pulsed Phase thermography is an active thermography where analysis is made in the transient mode. It is a link between pulsed thermography and lockin thermography. In pulsed thermography, a pulse of heat is applied to the surface of the specimen. Here the measurement is made in the transient state. But in lockin thermography, the specimen is subjected to sinusoidal thermal stimulation. Here the measurement is made in the steady state. Here using this method large area like 30 feet $^{2}$ can be inspected simultaneously. The advantage of this method is both phase and modulation images are available and phase is less affected by heating anisotropy. Maximum depth of penetration of phase is twice the depth of penetration of amplitude. Here modulated ultrasonic heating can be used. The Thermal diffusion length $\mu$ is given as $\mu=\sqrt{ } 2 \alpha / \omega$, where $\alpha$ is thermal diffusivity and $\omega$ is angular frequency and $\omega=2 \prod \mathrm{f}$, where $f$ is the frequency. The disadvantage in pulsed phase thermography is that it requires modulated thermal perturbation and observation for at least one modulation cycle ie longer than pulsed thermography. Unknown defects might require multiple experimentations with different frequencies because the thickness of the inspected layer under the surface is related to the modulation frequency. Pulsed Phase thermography can be used in aircraft structural component inspection, loose bolts detection, Crack identification, particularly vertical crack identification, disbonding, impact damage in carbon FRP, adhesion strength study, depth profile study of thermal conductivity or thermal diffusivity, anisotropic material characterization moisture evaluation, coating thickness in ceramics, etc.

Step heating thermography is an active thermography which is sometimes referred to as long pulse thermography or time-resolved infrared radiometry. Here the increase in surface temperature is monitored during the application of a step heating pulse. In most infrared radiometric techniques of non-destructive testing, the sample cools after pulsed heating. In contrast, the technique of time-resolved infrared radiometry with step heating follows the surface temperature rise as a function of time during the heating pulse. Step heating thermography finds numerous solicitations such as coating thickness appraisal (comprising multi-layered coatings), examination of coating-to-substrate bond or assessment of complex assemblies. This tactic allows identification of subsurface features and determination of thermal characteristics with the similar speed as other thermal 
practices. Time-resolved infrared radiometry with step heating results in smaller heating intensities compared to the more common short pulse procedures. But it keeps the required heating power and resulting surface temperature small. Though thermal non-destructive testing procedures generally concentrate on discontinuity detection and imaging, time-resolved infrared radiometry with step heating has also been used effectively to determine material parameters such as thermal diffusivity and width. This has allowed information about material structure such as the presence of corrosion, porosity or voids to be obtained. Time-resolved infrared radiometry with step heat. This wavelength separation usually requires a laser source. Heating requires wavelength separation between the heating source and the detector. Here wavelength separation usually requires a laser source. Heating requires wavelength separation between the heating source and the detector. Major advantages of step heating technique over pulsed techniques are that the power requirements of the heating source are lower, making it applicable to many non-optical or single-wavelength heating sources. Further, it allows pixel-to-pixel calibration without a reference sample. Images of disbond depth or thermal properties can be generated with a simple and fast algorithm. It also has been shown that the blurring of small or deeply buried discontinuities by lateral diffusion is reduced for step heating.

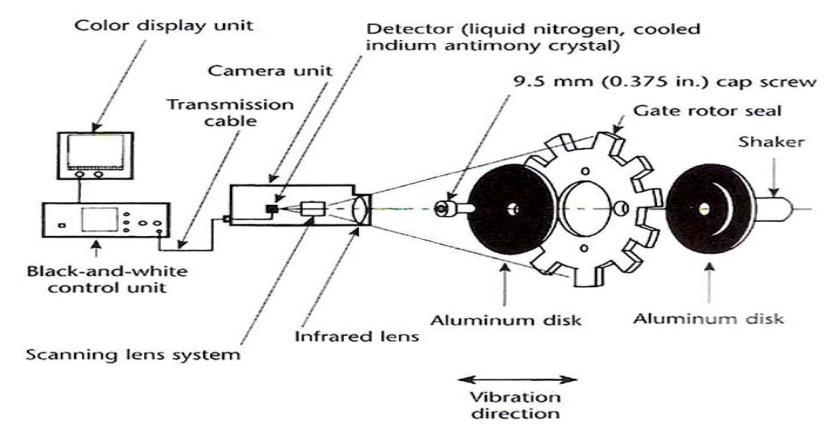

Fig. 34. Vibro thermographic inspection of Gate rotor seal

Vibrothermography is an active IR thermographic procedure where under the influence machine-driven pulsations $(20$ to $50 \mathrm{~Hz}$ ) are persuaded superficially to the assembly because of unswerving transformation from mechanical to thermal vitality. Heat is liberated by resistance precisely at discontinuities such as fissures and delaminations. Discontinuities are agitated at precise mechanical echoes to find out the flaws.

Transient thermography is valid for the discovery of engrained blemishes in resources with small heat conductivity. The trial is excited up over an elongated interval in an incinerator (ND heat, e.g. $50^{\circ} \mathrm{C}$ ). Afterward, it is moved to a regular weather, and the exterior heat is measured by means of IR camera. As the trial is dropping heat to the surroundings due to convection and emission, the exterior will be chilling down. Warmness is rolling from the inner to the outward of the model. An imperfection, characteristically a delamination or void, is a thermal obstacle for the heat current which clues to an inhomogeneous hotness dispersal on the exterior and is spotted by IR camera. The hotness must shield only semi-distance linked to other warm air procedures. This elucidates, why it is probably to identify deep-rooted blemishes in tiny time using this routine.

\section{Application \& Cost in Industries}

The belt conveyor system is used for material handling and reduces human efforts in material transportation and also minimizes the cost of the application [81]. These conveyors also play a key role in continuous assembly plants especially in packaging industries [82]. Conveyor systems are largely employed in object sorting and counting facility [83], handling crushed limestone[84], crushed biomass wood handling[85], cooling of moulds[86], sugar industry[87], mining industries[88], apparel industry, transporting cartons and totes[89], thermal power plant[90], coal handling[91], etc. The band dryer utilizes a conveyor system to the drying chamber. So, the final product looks like a combo of band dryer and conveyor system. The discussed type is given below.

Band Dryers: For generally free-streaming granules and extrudates that may experience mechanical harm on the off chance that they are scattered, band dryers are a decent choice. It is basically a conveyor dryer wherein the band is a punctured band over which the bed of drying materials rests. Drying air at rather low speeds streams upwards through the band to achieve drying. Unmistakably, this sort of dryer is anything but a decent decision for exceptionally wet or fine solids. Gas cleaning necessities are negligible as low gas speeds are utilized. Likewise, power prerequisites for air dealing with are very low because of the low-pressure drops required. In business plans of extensive band dryers, it is imperative to guarantee uniform circulation of the item on the band and furthermore uniform dissemination of the wind stream inside the chamber of the dryer to guarantee uniform item wetness content [45-47].

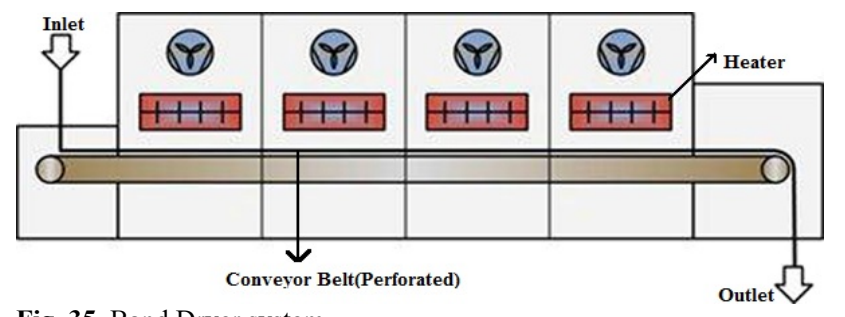

Fig. 35. Band Dryer system

Similarly dryers also play a foremost role in pharmaceutical industries[92], agricultural products[17], food industry[93], marine products[94], fruits drying[94, 95, 96, 97], porous bodies drying[98], timber drying[99], cereals drying[100, 101], paper drying[102, 103, 107], fabric drying[104], cement industry[105, 106], printing, drug drying[109], sludge and faecal materials from sanitation processes[108], laundry[110], etc. Dryer installation is little expensive but is worthy enough to provide best results of removing moisture from resources. Thermography is mainly utilized for non-destructive analysis, fault analysis, and medical analysis. These applications can be further expanded into fields like investigation of historic structures[111], flat bottom hole analysis in slabs[112], loose electrical connections[113], sports medicine[114], dentistry[115], medical applications[116, 117], electrical motor applications[118], power plants[119], heater process[120], mechanical systems and hydraulic components[121], energy conservation[122], surveillance and security[123, 124, 125], civil constructions[126, 127], marine engineering applications[128], animal reproduction[129], defence systems and military applications[130, 131], dairy 
applications[132], pathological analysis in structures for building strength analysis and maintenance[133], automobile industries[134, 135, 138], gas leakage and detection[136, 137, 140], aerial survey of buried objects[139], agriculture[141], food processing industry[142, 143], food quality assessment[144], waste management[145], soil assessment[146], research and development works[147], printed circuit board fabrication \& solar cell diagnostics[148], etc. The applications extend to a larger range and only a few are discussed above. The thermography analysis is costlier and effective when compared to other non-destructive testing methods. The thermography camera which is chosen for the analysis is fluke make Tix 580 .

\section{Conclusion}

This survey article throws limelight on the overview of conveyor systems, dryers and thermography analysis. The combined architecture and modeling of conveyor based drier system uses convection laws for heat and moisture transfer at gaseous phases [149]. The thermographic analysis can be made to ensure the safety of the drying process from the identification of hotspots and monitoring the drying process for the thermal anomaly to guarantee that the process does not exceed the optimum operating temperature points. This survey article gives a better outline of all conveyor, band dryer and thermography analysis. This article would be very much helpful for researchers who seek information about conveyor and thermographic systems. The researchers can know these systems and utilize the design equivalences for a proper installation and application.

This is an Open Access article distributed under the terms of the Creative Commons Attribution License

\section{References}

[1] S.M.Math, S.B.Naik, "Review Of Finite Element Analysis Of Roller Conveyor For Material Handling System", International Journal of Advance Research in Science and Engineering, Vol.No.5, Issue No.4, pp - 668- 673, April 2016.

[2] Devendra Kumar, R.K.Mandloi, "Analysis \& Prospects of Modification in Belt Conveyors - A Review", International Journal of Engineering Research and Applications (IJERA) ISSN: 22489622, Vol. 3, Issue 1, January -February 2013, pp.581-587.

[3] D.K. Nannaware, R.R. Kharde, "Design and Optimization of Roller Conveyor System", International Journal of Scientific \& Engineering Research, ISSN 2229-5518, Volume 5, Issue 7, July-2014, pp - 1254 $-1258$.

[4] P.B.Chavan, A.M.Bobade, D.S.Mahale, V.R.Bhadane, "Review Paper on Low Cost Conveyor Design Reduction of Weight of Conveyor System", International Journal for Research in Applied Science \& Engineering Technology (IJRASET), ISSN: 2321-9653, Volume 5 Issue III, March 2017.

[5] Harishchandra A.Shire, B.D.Biranale, "A Review on Design and Experimental Analysis of Flight of Drag Chain Conveyor Belt with respect to its Breaking Strength by Varying Flight Material", International Journal of Science, Engineering and Technology Research (IJSETR), Volume 5, Issue 3, March 2016.

[6] Ashveer Singh, Shashank P.Joshi, Ronak R.Patel, "A Review on Design of Live Roller Conveyor System", International Journal of Science Technology \& Engineering, Volume 1, Issue 11, ISSN (online): 2349-784X, May 2015.

[7] Pranay S.Chaudhari, V.A.Kolhe, S.B.Ambekar, "A Review Paper on Flexible Spring Conveyor System for Material Handling System", International Research Journal of Engineering and Technology (IRJET), ISSN: 2395-0072, Volume: 03 Issue: 04, Apr-2016.

[8] Pradnyaratna A.Meshram, A.R.Sahu, "Design , Modeling and Analysis of conveyor system used for transportation of Cartons", International Journal of Research in Advent Technology, E-ISSN: 2321-9637, Vol.4, No.1, January 2016.

[9] Guofeng Yuan, Liang Hong, Xing Li, Li Xu, Wenxue Tang, Zhifeng Wang, "Experimental investigation of a solar dryer system for drying carpet", International Conference on Solar Heating and Cooling for Buildings and Industry, Energy Procedia 70(2015), pp $626-633$.

[10] S.S.Bhansali, Sonali nagargoje, Suraj Wasade, Amol Kanwale, "SOLAR DRYER SYSTEM (A REVIEW PAPER)", International Journal of Research In Science \& Engineering, ISSN: 2394-8280, Volume: 1, Issue:3, pp - 21 - 27.

[23] S.P.Singh, K.S.Jairaj, K.Srikant, "The development of solar dryers used for grape drying", First India International Energy Submit 2011

[24] Mohmand Hani, "Drying of the grape using dish type solar air heater", Journal of Agricultural Research, 50(3):423-431, 2012.

[25] R.Manikanta,K.N.Sheeba and S.Jaisankar, "Greenhouse solar dryer", August 2012, vol 6, Issue 1,:1554.

[26] Prof.M.Ramkrishnarao, "Innvotive solar food processing technology", August 2014.
[11] Gregory L.Wedel, Gerald L. Timm, "Effectiveness of Paper Dryer Journal Insulating Sleeves", PaperCon 2011, pp - 2826 -2842.

[12] Anju Katiyar,K. Sudhakar, "A review on the Tray Dryer System for Agricultural Products", December 2013.

[13] A.R. Celma, F. Cuadros, "Energy and exergy analyses of OMW solar drying process", Renewable Energy, doi:10.1016/j.renene.2008.05.019, pp-660-666, June 2008.

[14] Umesh Toshniwal, S.R Karale, "A review paper on Solar Dryer", International Journal of Engineering Research and Application(IJERA), ISSN: 2248-9622, Vol. 3, Issue 2, pp.896-902, March -April 2013.

[15] Turhan Koyuncu, "Performance of various design of solar air heaters for crop drying applications", Renewable Energy, doi:10.1016/j.renene.2005.05.017, pp-1073-1088, July 2005.

[16] Sadajad Abasi, Saeid Minaei, Mohammad Hadi Khoshtaghaza, "Performance of a Recirculating Dryer Equipped with a Desiccant Wheel", Drying Technology, Vol 34, No 8, pp-863-870, 2016.

[17] S.Misha, S. Mat, M.H.Ruslan, K.Sopian, E.Salleh, "Review on the Application of a Tray Dryer System for Agricultural Products", World Applied Sciences Journal 22 (3): 424-433, ISSN 1818-4952, 2013

[18] V.Yadav, C.G.Moon, "Fabric-drying process in domestic dryers", Applied Energy (85), doi:10.1016/j.apenergy.2007.06.007, pp-143158 , September 2007

[19] G.Schirripa Spagnolo, P.Del Vecchio, G.Makary, D.Papalillo, A.Martocchia, "A Review of IR Thermography applied to PV systems", IEEE International Conference on Environment and Electrical Engineering, 978-1-4577-1829-8/12/\$26.00 (C2012

[20] Dr.P.E.Chandra Mouli, Dr(Capt).S.Manoj Kumar, Dr.B.Senthil, Dr.S.Parthiban, Dr.A.E.Malarvizhi, Dr.R.Karthik, "Application of Thermography in Dentistry-A Review", Journal of Dental and Medical Sciences, ISSN: 2279-0853 Volume 1, Issue 1 (July-Aug. 2012), PP 39-43

[21] Jane Kerr, "Review of the effectiveness of infrared thermal imaging (thermography) for population screening and diagnostic testing of breast cancer", NZHTA TECH BRIEF SERIES, Volume 3, Number 3,July 2004.

[22] Rub'en Usamentiaga, Pablo Venegas, Jon Guerediaga, Laura Vega, Julio Molleda, Francisco G.Bulnes, "Infrared Thermography for Temperature Measurement and Non-Destructive Testing", Sensors, ISSN 1424-8220, pp-12305-12348, July 2014

[27] Sato, K., M. Katahira and E. Toji, "Drying characteristics of raw bulb and dehumidified air and moisture content distribution of different bulb parts", Journal of Japanese Society of Agricultural Machinery, Tohoku Branch, 44: 43-46, 1997.

[28] Miller, W.M., "Energy storage via desiccant for food agricultural applications", Energy in Agriculture, 2:341-354. http://dx.doi.org/10.1016/j.rser.2012.04.041, 1983. 


\section{Ajith. B. Singh, V. Rukkumani, P. Manju1, R. Srinivasan and Anie Selva Jothi.A/}

\section{Journal of Engineering Science and Technology Review 13 (1) (2020) 171 - 192}

[29] Okano, H., "Honeycomb rotor type dehumidifiers: comparison between honeycomb rotor type dehumidifiers and various dehumidifying new systems and explanation on their outlines", Clean Technology, 3: 33-37, 1998.

[30] Augustus Leon, M., S. Kumar and S.C. Bhattacharya, "A comprehensive procedure for performance evaluation of solar food dryers", Renewable and Sustainable Energy Reviews, 6: 367-393, 2002.

[31] Chua, K.J. and S.K. Chou, "Low-cost drying methods for developing countries", Trends in Food Science and Technology, 14: 519-528, 2003.

[32] “Supriya Engineering “, Coal Handling Plant Manual, Operation \& Maintenance manual.

[33] Lin-jing Xiao, Xiu-hua Sui, De-jun Miao, "Study on Mechanics of Driving Drum with Superelastic Convexity Surface Covering-Layer Structure", Elsevier Limited and Science Press, 2008.

[34] Di Perry L. Martin, Electronic Failure Analysis Handbook, New York, USA: McGraw-Hill Book Company, 2004. ISBN: 9780070410442

[35] R. Siege and J. Howell, Thermal Radiation Heat Transfer, New York, USA: McGraw-Hill Book Company, 1972. ISBN: 9780891162711.

[36] Maldague.X, "Theory and Practice of Infrared Technology for Nondestructive Testing", Wiley, New York, NY, USA, 2001.

[37] Modest.M.F,"Radiative Heat Transfer", Academic Press: Waltham, MA, USA, 2013.

[38] Vollmer.M, Möllmann.K.P,"Infrared Thermal Imaging: Fundamentals, Research and Applications", Wiley: Weinheim, Germany, 2011.

[39] Zissis.G.J, Wolfe.W.L, "The Infrared Handbook. Technical report", DTIC document, 1978.

[40] Gaussorgues.G, "Infrared Thermography", Springer: Berlin/Heidelberg, Germany, 1994.

41] Poonam Dhankhar, "Drying: Basic Food Preservation Method", The International Journal Of Science \& Technoledge, ISSN 2321 - 919X, vol 2, issue 5, pp - 235-244, may 2014

[42] Michael G. Kay, "Material Handling Equipment", North Carolina State University, pp - 1-67, January 2012

[43] A. I. Liapis, R. Bruttini, "Freeze-Drying of Pharmaceutica Crystalline and Amorphous Solutes in Vials: Dynamic MultiDimensional Models of the Primary and Secondary Drying Stages and Qualitative Features of the Moving Interface", Journal of Drying Technology, vol 13, issue 1-2, 1995.

44] Thanit Swasdisevi, Sakamon Devahastin, Poomjai Sa-Adchom, Somchart Soponronnarit, "Mathematical modeling of combined farinfrared and vacuum drying banana slice", Journal of food engineering, vol92, issue 1, pp - 100 - 106, may 2009.

[45] Kudra, T., Mujumdar, A.S., “Advanced Drying Technologies", Marcel Dekker, New York, 2000.

[46] Arun S. Mujumdar, "Dryers For Particulate Solids, Slurries And Sheet-Form Materials".

[47] Fundamental Aspects of drying by Taylor \& Francis Group, LLC.

[48] Arun S. Mujumdar, "Handbook of Drying Technologies", Marcel Decker Publications.

[49] Arun S. Mujumdar, "Classification and Selection of Industrial Dryers".

[50] Moore, J.G., Drum dryers, "Handbook of Industrial Drying", 2nd ed., Mujumdar, A.S., Ed., Marcel Dekker, New York, 1995, p. 249.

[51] C. T. Kiranoudis, Z. B. Maroulis, D. Marinos-Kouris, "Modelling and Design of Conveyor Belt Dryers", Journal of food engineering, Volume 23, Issue 3, Pages 375-396, 1994.

[52] Czeslaw Strumillo, Tadeusz Kudra, "Drying: Principles, Applications, and Design", CRC Press, 1986.

[53] I. A. Daniyan , A. O. Adeodu, O. M. Dada, "Design of a Materia Handling Equipment: Belt Conveyor System for Crushed Limestone Using 3 roll Idlers" Journal Of Advancement In Engineering And Technology, vol 1, issue 1, ISSN - 2348 - 2931, pp 1-7, Jan 2014.

[54] Rulmeca. Technical information, "Project and Design Criteria for Belt conveyors", Pp. 1-50.

[55] Taiwo.A, Jekayinka.S.O, Onawumi.S.A, "Mechanical Maintenance and Repairs', Orsome Ventures Ltd, Ibadan, pp 50-70, 2005.

[56] Anath.K.N, Rakesh.V, "Design and Selecting Proper Conveyor Belt", International Journal of Advanced Technology, Vol. 4(2) pp 43-49, 2013.

[57] Fenner Dunlop “Conveyor Handbook”, Conveyor Belting Australia, pp 1-70, 2009.

[58] Besser Service Bulletin. (2006). Conveyor Belt Basic Rules and Procedure for Tracking. pp. 1-7.
[59] Phoenix Conveyor Belt Systems. (2004). Design Fundamentals. Hamburg pp. 1-16.

[60] ABB-Process Industries (2000). Variable-speed drives for Belt Conveyor Systems. Pp. 1-7.

[61] Sandvik, "Conveyor Components", pp- 1- 8, 2000

[62] Orthman Conveying System, "Belt Conveyor Catalogue", pp - 1-21, 2004.

[63] Conveyor Equipment Manufacturers Association (CEMA), "Belt Conveyors for Bulk Materials" 6th Edition, pp. 200-205.

[64] Hayder Abdulnabi Thajeel, "Numerical modeling of infrared thermography techniques via ANSYS", Scholar's Mine, Masters Theses. 7344, 2013.

[65] C.Meola, G.M.Carlomagno, "Recent advances in the use of infrared thermography', Measurement Science and Technology, 15(9):R27, 2004

[66] Ehsan Borazjani, "Inverse Heat Conduction Approach for Infrared Non-destructive Testing of Single and Multi-Layer Materials", Ottawa, Canada, 2012.

67] Clemente Ibarra Castanedo, "Quantitative subsurface defect evaluation by pulsed phase thermography: depth retrieval with the phase", 2005.

[68] E.M.Sparrow, R.D.Cess, "Radiation heat transfer", Hemisphere Publication Corporation, 1978.

69] Fabio Luzi, Malcolm Mitchell, Leonardo Nanni Costa, Veronica Redaelli, "Thermography: Current Status And Advances In Livestock Animals And In Veterinary Medicine", Handbook, Brescia, marzo 2013

[70] JOHN H. LIENHARD IV, JOHN H.LIENHARD V, "A Heat Transfer textbook", 3rd ed., accessed on Aug 2003

[71] INCROPERA.F.P, DE WITT.D.P, "Fundamentals of Heat and Mass Transfer", 3rd edition, John Wiley \& Sons, 1990 USA.

[72] Seán M. Stewart, "Spectral Peaks and Wien's Displacement Law", JOURNAL OF THERMOPHYSICS AND HEAT TRANSFER, Vol. 26, No. 4, October-December 2012

[73] Clemente IBARRA-CASTANEDO, Abdelhakim BENDADA, Xavier P.V. MALDAGUE, "Infrared vision applications for the nondestructive testing of materials", 5th Pan American Conference for NDT, 2-6 October 2011, Cancun, Mexico.

[74] X.P.V. Maldague, "Theory and Practice of Infrared Technology for Nondestructive Testing", Wiley, New York (2001)

[75] Maldague.X.P.V, Streckert.H.H, Trimm.M.W, "Introduction to infrared and thermal testing: Part 1. Nondestructive testing," in Nondestructive Handbook, Infrared and Thermal Testing, Volume 3, X. Maldague technical ed., P. O. Moore ed., 3rd edition, Columbus, Ohio, ASNT Press, p.151, 2001

76] Vollmer.M, Mollmann.K.P, "Infrared Thermal Imaging Fundamentals, Research and Applications", Wiley: Weinheim, Germany, 2011.

77] A.Sophian, G.Y.Tian, D.Taylor, J.Rudlin, "A feature extraction technique based on principal component analysis for pulsed eddy current ndt", NDT \& E International, 36(1):37-41, 2003.

[78] Rub'en Usamentiaga, Pablo Venegas, Jon Guerediaga, Laura Vega , Julio Molleda, Francisco G. Bulnes, "Infrared Thermography for Temperature Measurement and Non-Destructive Testing", Sensors (Basel), 10;14(7):12305-48, Jul 2014.

[79] HIS GlobalSpec, Optical Components and Optics, Wavelength Range,

http://www.globalspec.com/learnmore/optics_optical_components/ optical components/achromats, accessed on Aug 2018.

[80] VISirX NDT-Infrared Vision, Technology, http://www.visirx.com/en/infrared-thermography-technology, accessed on Aug 2018 .

[81] Abhijit Gaikwad, Yogesh Raut, Jitendra Desale, Akshay Palhe, Govinda Shelar, Prof.Shreekant Pawar, "Design and Development of Automated Conveyor System for Material Handling", IOSR Journal of Mechanical and Civil Engineering (IOSR-JMCE), e-ISSN: 2278 1684,p-ISSN: 2320-334X, PP 31-34, 2017.

[82] K.V.Krishna Sastry, Pawan Kumar Sahu, Prince Kumar, "Development Of A Prototype Of Industrial Conveyor Using Four Bar Mechanism", International Journal of Pure and Applied Mathematics, Volume 118, No. 5, pp-969-973, 2018.

[83] Nasif Hassan Khan, Deb Kumar Sarkar, Asif Siddique, Md.Mamunur Rahman, Swarup Chakraborty, "Fabrication of a Conveyor Belt with Object Sorting and Counting Facility", International Journal of Advancements in Research \& Technology, Volume 6, Issue 5, ISSN 2278-7763, May-2017.

[84] I.A.Daniyan, A.O.Adeodu, O.M.Dada, "Design of a Material Handling Equipment: Belt Conveyor System for Crushed Limestone 


\section{Ajith. B. Singh, V. Rukkumani, P. Manju1, R. Srinivasan and Anie Selva Jothi.A/}

\section{Journal of Engineering Science and Technology Review 13 (1) (2020) 171 - 192}

Using 3 roll Idlers," Journal of Advancement in Engineering and Technol-ogy, vol.1, no.1, 2014

[85] Aniket A Jagtap, Shubham D Vaidya, Akash R Samrutwar, Rahul G Kamadi, Nikhil V Bhende, "Design of Material Handling Equipment: Belt Conveyor System for Crushed Biomass Wood Using V Merge Conveying System," International Journal of Mechanical Engi-neering and Robotics Research, vol.4, no.2, 2015.

[86] Seema S.Vanamane, Pravin A.Mane, "Design Manufacture and Analysis of Belt Conveyor System used for Cooling of Mould," Inter-national Journal of Engineering Research and Applications (IJERA), vol.2, no. 3, 2012.

[87] Memane Vijay, Prof. N. S. Biradar, "Design and Analysis of Belt Conveyor System of Sugar Industry for Weight Reduction,” Journal of Emerging Technologies and Innovative Research (JETIR), vol.2, no. 5,2015

88] S.E.Gavrishev, K.V.Burmistrov, N.G.Tomilina, "Increasing the Work Scope of Conveyor Transport at Mining Companies", International Conference on Industrial Engineering, (ICIE), Procedia Engineering 150, pp-1317 - 1321, 2016.

[89] Vijay M. Patil, Niteshkumar A.Vidya, Roshan L. Katkar, Piyush S. Pande, "Type of Conveyor System: A Review", IJSRD International Journal for Scientific Research \& Development, Vol. 2 Issue 12, ISSN (online): 2321-0613, 2015.

[90] Raghvendra Singh gurjar, Arvind yadav, Pratesh jayaswal, "Failure analysis of belt conveyor system in a thermal power plant", International Journal of Advanced Technology \& Engineering Research (IJATER), ISSN NO: 2250-3536, VOLUME 2, ISSUE 3 , pp-195-200, May 2012.

[91] Lihua ZHAO, Yin LIN, "Operation and Maintenance of Coa Handling System in Thermal Power Plant", First International Symposium on Mine Safety Science and Engineering, Procedia Engineering 26, pp-2032 - 2037, 2011.

[92] C.J.Aundhia, J A.Raval, M.M.Patel, N.V Shah, S.P.Chauhan, G.U.Sailor, A.R.Javia, R.A.Mahashwari, "Spray Drying in the Pharmaceutical Industry - A Review", Indo American Journal of Pharmaceutical Research, 2(1)pp-125-138, ISSN NO 2231-6876, 2011.

[93] Gül ah Çakma, Cengiz Y ld z, "Design of a new solar dryer system with swirling flow for drying seeded grape", International Communications in Heat and Mass Transfer, 36: pp-984-990, 2009.

[94] Fudholi.A, K.Sopian, M.H.Ruslan, M.A.Alghoul, M.Y.Sulaiman, "Review of solar dryers for agricultural and marine products", Renewable and Sustainable Energy Reviews, 14: pp-1-30, 2010.

[95] Sarsilmaz.C, C.Yildiz, D.Pehlivan, "Drying of apricots in a rotary column cylindrical dryer (RCCD) supported with solar energy", Renewable Energy, 21: pp-117-127, 2000.

[96] El-Beltagi.A, G.R.Gamea, A.H.A.Essa, "Solar drying characteristics of strawberry", Journal of Food Engineering, 78: pp-456-464, 2007.

[97] Mathioulakis.E, V.T.Karathanos, V.G.Belessiotis, "Simulation of air movement in a dryer by computational fluid dynamics: Application for the drying of fruits", Journal of Food Engineering, 36: pp-183200, 1998.

[98] Lamnatou.Chr, E.Papanicolaou, V.Belessiotis, N.Kyriakis, "Finitevolume modelling of heat and mass transfer during convective drying of porous bodies - Non-conjugate and conjugate formulations involving the aerodynamic effects", Renewable Energy, 35: pp1391-1402, 2010

[99] Cronin.K, B.Norton, J.Taylor, "Development of a simulation tool to enable optimisation of the energy consumption of the industrial timber-drying process", Applied Energy, 53: pp-325-340, 1996.

[100] D.B.Sauer, "Drying of grain Chapter IX, Storage of cereal grains and their products", American Association of Cereal Chemists, 1992.

[101] Hukill WV, Schmidt JL, "Drying rate of fully exposed grain kernels", Transactions of the ASAE, 3(2) pp-0071-0077, 1960.

[102] J.Cesar Monzon, "Electromagnetic Paper Drying", IEEE TRANSACTIONS ON MICROWAVE THEORY AND TECHNIQUES, VOL. 43, NO. 2, FEBRUARY 1995.

[103] HENG-DE KUANG, JULES THIBAULT, BERNARD P.A GRANDJEAN, RUBIE CHEN, "STUDY OF HEAT AND MASS TRANSFER DURING IR DRYING OF PAPER", Drying Technology: An International Journal, 12(3), pp-545-575, 1994.

[104] Lyman Fourt, Arnold M. Sookne, Daniel Frishman, Milton Harris, "The Rate of Drying of Fabrics", Volume: 21, issue: 1, page(s): 2633, January 1, 1951.

[105] Satoru Hirose, "Waste Management Technologies in Japanese Cement Industry - from Manufacturing to Ecofactuaring", Journal of Water and Environment Technology, Vol.2, No.1, 2004.
[106] Yousef S.H.Najjar, Douglas Waite, "Energy conservation and waste utilization in the cement industry serve the green technology and environment", International Journal of Sustainable Engineering, volume 9, issue 1, Dec 2014

[107] Ajit K Ghosh, "Fundamentals of Paper Drying - Theory and Application from Industrial Perspective", http://www.intechopen.com/books/evaporation-condensation-andheat-transfer/fundamentalsof-paper-drying-theory-and-applicationfrom-industrial-perspective, pp - 535 - 582, 2011.

108] Linda Strande, Mariska Ronteltap, Damir Brdjanovic, "Faecal Sludge Management (FSM) book - Systems Approach for Implementation and Operation", IWA Publishing, ISBN: 9781780404721, 2014.

109] Jens Burgbacher, Jacques Wiss, "Industrial Applications of Online Monitoring of Drying Processes of Drug Substances Using NIR", Organic Process Research \& Development, Volume 12, Issue 2, pp235-242, 2008

[110] Shi Yao-jun, Wu Nai-qun, Dai Ye, "Research on Innovative Design of Portable Quick-drying Machine", International Journal of Control and Automation, Vol. 8, No. 1, pp- 149-156, 2015.

111] N.P.Avdelidis, A.Moropoulou, "Applications of infrared thermography for the investigation of historic structures", Journal of Cultural Heritage, volume 5, issue 1, pp- 119-127, 2004.

112] Maria Frendberg Beemer, Steven M. Shepard, "Aspect ratio considerations for flat bottom hole defects in active thermography", Quantitative InfraRed Thermography Journal, ISSN: 1768-6733, 2017.

113] Richard A.Epperly, G.Erich Heberlein, Lowry G.Eads, "Thermography, A Tool for Reliability and Safety", IEEE Industry Applications Magazine, Jan 1999.

114] Carolin Hildebrandt, Christian Raschner, Kurt Ammer, "An Overview of Recent Application of Medical Infrared Thermography in Sports Medicine in Austria", Sensors, ISSN 1424-8220, Volume 10, Issue 5, 2010

115] Dr.P.E.Chandra Mouli, Dr(Capt).S.Manoj Kumar, Dr.B.Senthil, Dr.S.Parthiban, Dr.A.E.Malarvizhi,Dr.R.Karthik, "Application of Thermography in Dentistry-A Review", IOSR Journal of Dental and Medical Sciences, ISSN: 2279-0853 Volume 1, Issue 1, July-Aug. 2012

116] B.B.Lahiri, S.Bagavathiappan, T.Jayakumar, John Philip, "Medical applications of infrared thermography: A review", Infrared Physics \& Technology, Volume 55, Issue 4, pp-221-235, 2012.

[117] W.C.Amalu, W.B.Hobbins, J.F.Head, R.L.Elliot, "Infrared imaging of the breast - an overview", J.D. Bronzino (Ed.), Biomedical Engineering Handbook, third ed., Medical Devices and Systems, CRC Press, pp. 20, 2006.

[118] D. Lopez-Perez, J. Antonino-Daviu, "Application of Infrared Thermography to Failure Detection in Industrial Induction Motors: Case Stories", IEEE Transactions on Industry Applications, Volume 53, Issue 3, May-June 2017

119] Stanisław Łopata, Monika Kocot, "The conditions for thermographic testing of thermal power engineering installations", MECHANICS, TECHNICAL TRANSACTIONS 10/2017.

120] Noble Jimmy, Jojo Varghese, jithin k joy, Sebin Thomas, "Analysi of Industrial Process Heater using Thermography", International Research Journal of Engineering and Technology (IRJET), e-ISSN: 2395-0056, Volume 05, Issue 02, Feb-2018.

[121] R.A.Thomas, N.Jones, K.E.Donne, "Infrared thermography in industrial diagnostics", Measurement \& Control, Volume 34, pp110-112, May 2001.

122] Charles W.Hurley, Kenneth G.Kreider, "Applications for thermography for energy conservation in industry", U.S. DEPARTMENT OF COMMERCE, National Bureau of Standards Technical Note 923, Oct 1976.

123] Mate Krišto, "Review Of Methods For The Surveillance And Access Control Using The Thermal Imaging System", Review Of Innovation And Competitiveness, Volume2, Issue 4, 2016

[124] Sonika Obheroi, Vetrivelan P, "Design and Analysis of Airborne Thermo Graphic Cameras for Night Vision in Maritime Surveillance Applications", International Journal of Engineering Research in Electronic and Communication Engineering (IJERECE) Vol 3, Issue 3, March 2016

[125] Wai Kit Wong, Poi Ngee Tan, Chu Kiong Loo, Way Soong Lim, "An Effective Surveillance System Using Thermal Camera", International Conference on Signal Acquisition and Processing, pp13-17, 2009

[126] D.S.Prakash Rao, "Infrared thermography and its applications in civil engineering", The Indian Concrete Journal, pp-41-50, 2009. 


\section{Ajith. B. Singh, V. Rukkumani, P. Manju1, R. Srinivasan and Anie Selva Jothi.A/}

\section{Journal of Engineering Science and Technology Review 13 (1) (2020) 171 - 192}

[127] Walter Wild, "Application of infrared thermography in civil engineering", Proc. Estonian Acad. Sci. Eng., volume 13, issue 4, pp436-444, 2007.

[128] Vladimir PAŠAGIĆ, Marijan MUŽEVIĆ, Dubravko KELENC, "Infrared Thermography in Marine Applications", Shipbuilding: Theory and Practice of Naval Architecture and Naval Techniques, Vol 59, No 2, June 2008.

[129] Ivana KNÍŽKOVÁ, Petr KUNC, Gürkan Alp Kağan GÜRDİL, Yunus PINAR, Kemal Çağatay SELVI, "Applications of infrared thermography in animal production", Anadolu Journal of Agricultural Sciences (Turkey), ISSN : 1308-8769, pp-329-336, 2007.

[130] Aparna Akula, Ripul Ghosh, H K Sardana, "Thermal Imaging And Its Application In Defence Systems", Optics: Phenomena, Materials, Devices, and Characterization, AIP Conference Proceedings 1391, pp-333-335, 2011.

[131] Murat Kilinc, Osman Torunoglu, Hasan Kocer, "The Effect Of Viewing Angle On Detection Of Landmines From Thermal Time Series Images Using Active Thermography", International Journal of Energy Applications and Technologies, Vol 4, Issue 1, pp. 1-6, 2017.

[132] A. Colak, B. Polat, Z. Okumus, M. Kaya, L.E. Yanmaz, A. Hayirli, "Short Communication: Early Detection of Mastitis Using Infrared Thermography in Dairy Cows", Journal of Dairy Science, Volume 91, Issue 11, Pages 4244-4248, Nov 2008.

[133] Fábio Fernando Honório Farias, Romildo Alves Berenguer, Eliana Cristina Barreto Monteiro, Fernando Artur Nogueira da Silva, "Analysis of technics of thermography in predictive maintenance case study", Electronic Journal of Geotechnical Engineering, Vol. 21, Bundle 9, pp-3089-3104, 2016.

[134] "Thermography in the Automotive Industry", www.infratecinfrared.com, accessed on September 2018

[135] Akinaru Iino, Kenji Tsukamoto, Masanobu Kusakabe, "Estimation of radiant temperature and emissivity of automobile's surface using infrared thermography", SICE 2003 Annual Conference (IEEE Cat. No.03TH8734), Aug 2003.

[136] G Tanda, M Migliazzi, V Chiarabini, P Cinquetti, "Application of close-range aerial infrared thermography to detect landfill gas emissions: a case study", 34th UIT Heat Transfer Conference, Journal of Physics: Conference Series, Volume 796, Number 1, pp$1-10,2016$

[137] Amanda W. Lewis, Sam T.S. Yuen, Alan J.R. Smith, "Detection of gas leakage from landfills using infrared thermography applicability and limitations", Waste Management Research, Vol 21, Issue 5, pp-436-447, 2003

[138] Anna Stoynova Andonova, "Infrared Thermography In Aid Of Electric Vehicle Development And Exploitation", International Journal of Automobile Engineering Research and Development (IJAuERD), ISSN 2277-4785, Vol. 3, Issue 1, pp-27-34, Mar 2013.
[139] Jesse Casana, John Kantner, Adam Wiewel, Jackson Cothren, "Archaeological aerial thermography: a case study at the Chaco-era Blue J community, New Mexico", Journal of Archaeological Science, Volume 45, pp-207-219, May 2014.

[140] Luyu Ding, Daming Dong, Leizi Jiao, Wengang Zheng, "Potential using of infrared thermal imaging to detect volatile compounds released from decayed grapes", Public Library of Science, pp-1-11, June 30, 2017.

[141] Roselyne Ishimwe, K. Abutaleb, F. Ahmed, "Applications of Thermal Imaging in Agriculture - A Review", Advances in Remote Sensing, Vol.3, No.3, pp-128-140, 2014.

[142] R. Vadivambal, Digvir S.Jayas, "Applications of Thermal Imaging in Agriculture and Food Industry-A Review" Food Bioprocess Technology, Volume 4, Issue 2, pp-186-199, 2011.

[143] LUCIAN CUIBUS, "Applications of infrared thermography in the food industry", Dissertation thesis, ISSN: 2038-7946, 2013.

[144] A.A.Gowen, B.K.Tiwari, P.J.Cullen, K.McDonnell, C.P.O'Donnell, "Applications of thermal imaging in food quality and safety assessment", Trends in Food Science \& Technology, Volume 21, Issue 4, Pages 190-200, April 2010.

[145] Fjelsted.L.Thomasen, T. B.Valbjørn, I. L.Scheutz, Charlotte.A.G. Christensen, Kjeldsen.P, "Development of an innovative uavmountd screening tool for landfill gas emisiions", Fifteenth International Waste Management and Landfill Symposium, Proceedings Sardinia, 2015.

[146] Miguel Urrestarazu, "Infrared thermography used to diagnose the effects of salinity in a soilless culture", Quantitative InfraRed Thermography, Vol. 10, No. 1, pp-1-8, 2013.

[147] Jorge Henrique Bidinotto, Eduardo Morgado Belo, "Modal Shape Analysis Using Thermal Imaging", Journal of Aerospace Technology and Management, vol.7, no.2, São José dos Campos, pp.185-192, Apr./June 2015.

[148] "THERMAL IMAGING FOR R\&D / SCIENCE APPLICATIONS", www.flirmedia.com, accessed on september 2018

[149] Duško R.SALEMOVIC, Aleksandar Dj. DEDIC, Nenad Lj. CUPRIC, "A Mathematical Model And Simulation Of The Drying Process Of Thin Layers Of Potatoes In A Conveyor-Belt Dryer", Thermal Science, Vol. 19, No. 3, pp. 1107-1118, 2015.

[150] E.F.Zanoelo, A.Abitante, L.A.C.Meleiro, "Dynamic modeling and feedback control for conveyors-belt dryers of mate leaves", Journal of Food Engineering, Volume 84, Issue 3, pp-458-468, 2008.

[151] Omar F.Lutfya, Hazlina Selamat, S.B.Mohd Noor, "Intelligent Modelling and Control of a Conveyor-Belt Grain Dryer Using a Simplified Type-2 Neuro-Fuzzy Controller", Journal Drying Technology, Volume 33, Issue 10, Pages 1210-1222, 2015. 